Portland State University

PDXScholar

1990

\title{
Elementary Teachers' Perceptions of Their Instructional Styles in the Teaching of Conflict Resolution
}

Marcia Gregor Garrick

Portland State University

Follow this and additional works at: https://pdxscholar.library.pdx.edu/open_access_etds Let us know how access to this document benefits you.

\section{Recommended Citation}

Garrick, Marcia Gregor, "Elementary Teachers' Perceptions of Their Instructional Styles in the Teaching of Conflict Resolution" (1990). Dissertations and Theses. Paper 1132.

https://doi.org/10.15760/etd.1131

This Dissertation is brought to you for free and open access. It has been accepted for inclusion in Dissertations and Theses by an authorized administrator of PDXScholar. Please contact us if we can make this document more accessible: pdxscholar@pdx.edu. 


\title{
ELEMENTARY TEACHERS' PERCEPTIONS OF THEIR INSTRUCTIONAL STYLES IN THE TEACHING OF CONFLICT RESOLUTION
}

by

MARCIA GREGOR GARRICK

A dissertation submitted in partial fulfillment of the requirements for the degree of

\author{
DOCTOR OF EDUCATION \\ in \\ EDUCATIONAL LEADERSHIP: \\ EDUCATIONAL ADMINISTRATION AND SUPERVISION
}

Portland State University

(C) 1990 
TO THE OFFICE OF GRADUATE STUDIES:

The members of the committee approve the dissertation of Marcia Gregor Garrick presented April 11, 1990.
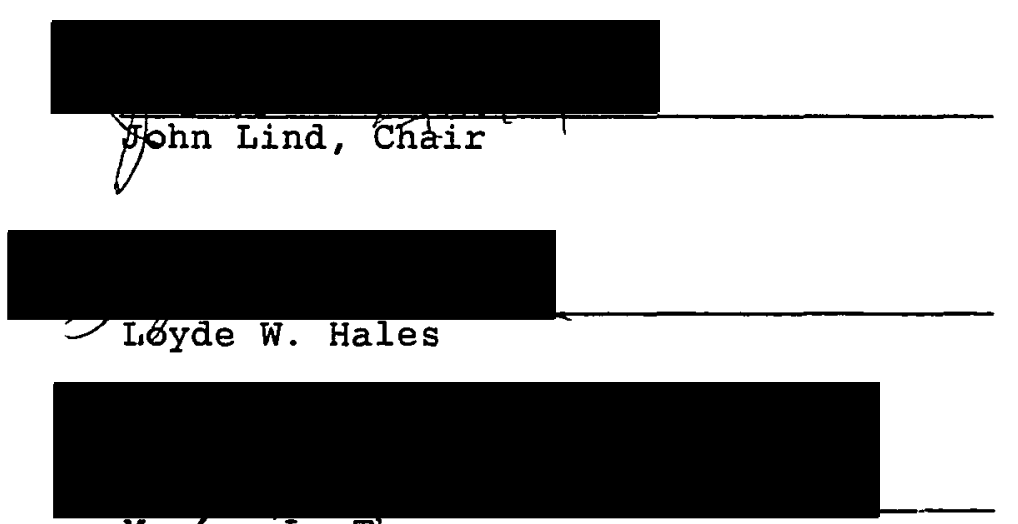

Maxpne I. Thomas

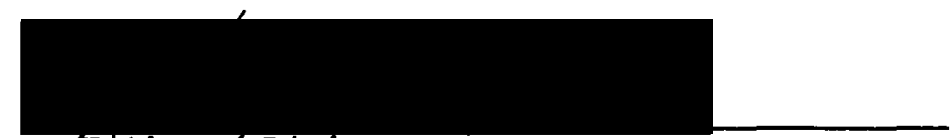

Kathryn' Dickson

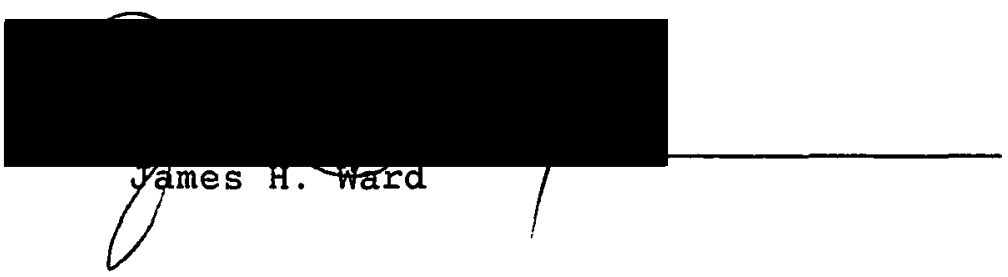

APPROVED :

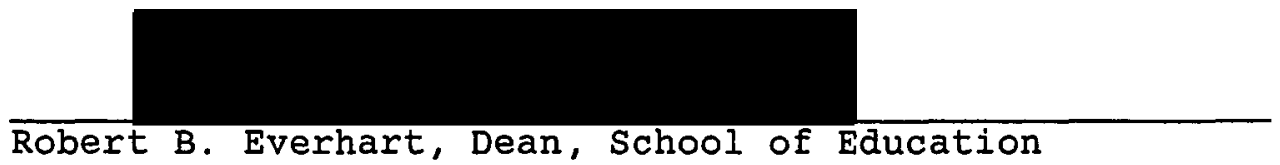

C. William Savery, Interim viof Provost for Graduate studies and Research 
ACKNOWLEDGEMENTS

Special recognition and sincere appreciation are extended to the committee members: Dr. John Lind (Chair), Dr. Loyde Hales, Dr. Maxine Thomas, Dr. Katherine Dickson and Dr. James Ward. Their time, expertise, support and guidance toward the development and completion of this research is respectfully acknowledged.

Recognition is given to the many teachers in the McMinnville, Newberg and West Linn School Districts who participated in the study, sharing valuable ideas. Recognition is also given to Dr. Ross Quackenbush for his computer expertise, to Dr. Lon Fendall for sharing his considerable knowledge and resources in Conflict Resolution, and to Carla Hopp for her editing, typing and patience.

I extend my sincere appreciation to my family and friends for their patience and interest. I offer special thanks to Teresa, William, Emily, Catherine and John Garrick for their faith and encouragement. 
TABLE OF CONTENTS

PAGE

ACKNOWLEDGEMENTS $\ldots \ldots \ldots \ldots \ldots \ldots \ldots \ldots \ldots \ldots \ldots \ldots \ldots \ldots \ldots \ldots$

LIST OF TABLES $\ldots \ldots \ldots \ldots \ldots \ldots \ldots \ldots \ldots \ldots \ldots \ldots \ldots \ldots \ldots \ldots \ldots$

CHAPTER

I INTRODUCTION $\ldots \ldots \ldots \ldots \ldots \ldots \ldots \ldots \ldots \ldots \ldots$

Statement of the Problem ........... 1

Purpose of the study $\ldots \ldots \ldots \ldots \ldots \ldots \ldots$

Significance of the Study $\ldots \ldots \ldots \ldots \ldots .5$

Research Questions .............. 6

Primary Questions ............. 6

Secondary Questions ........... 6

Assumptions $\ldots \ldots \ldots \ldots \ldots \ldots \ldots \ldots \ldots$

Limitations of the study ........... 7

Organization of the Document ........ 7

II IITERATURE REVIEW $\ldots \ldots \ldots \ldots \ldots \ldots \ldots \ldots \ldots \ldots$

Overview of Literature $\ldots \ldots \ldots \ldots \ldots \ldots .9$

Role Plays................... 14

Instruction in

Conflict Resolution ............. 15

Communication Techniques ......... 17

Classroom Discussion ............. 19

Drama, Literature and Art ......... 21

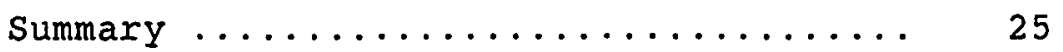




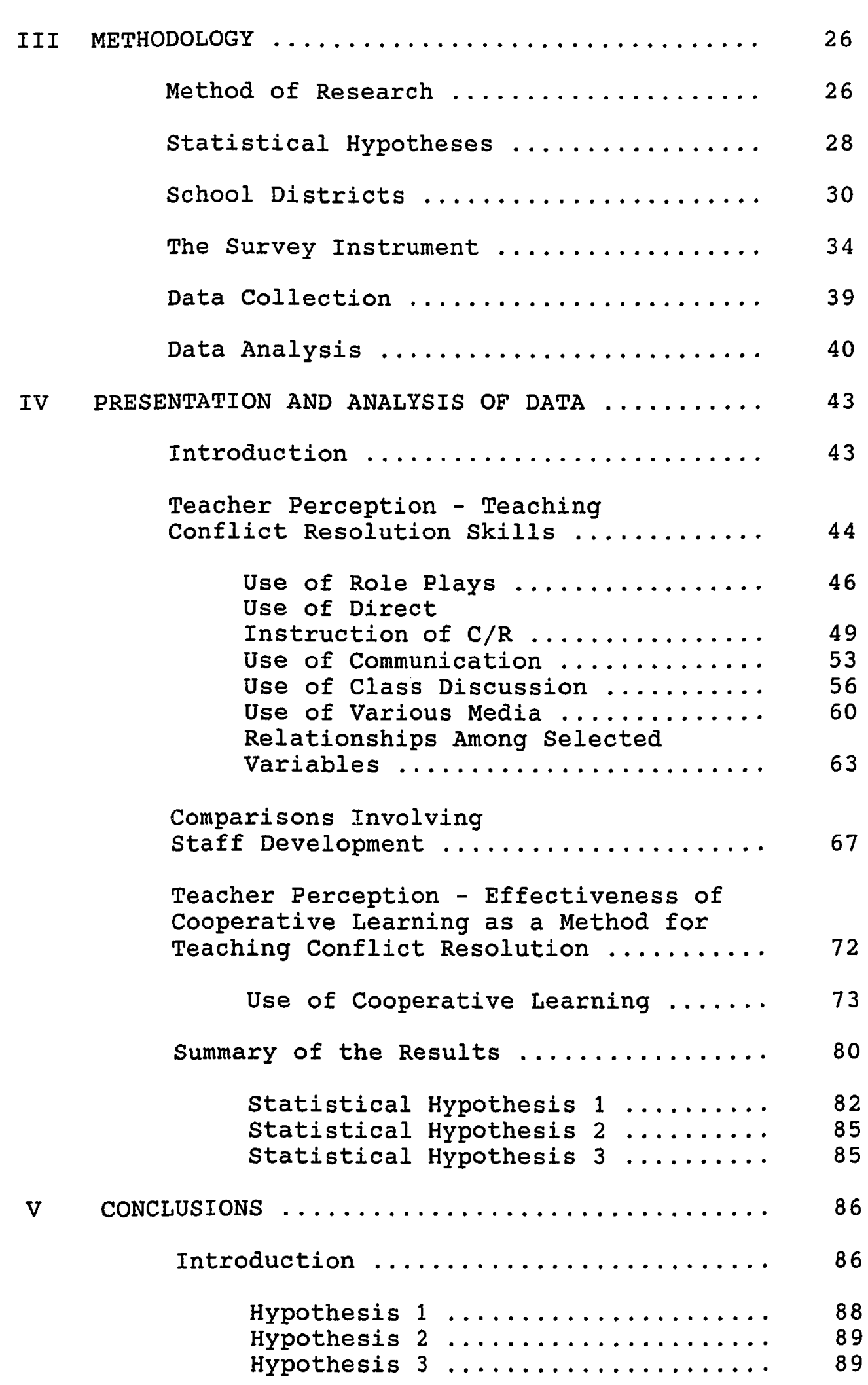


Summary Research Questions ......... 91

Questions 1,2 and $3 \ldots \ldots \ldots . \ldots 9$

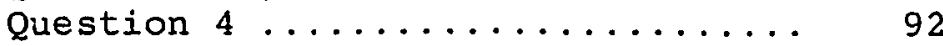

Question $5 \ldots \ldots \ldots \ldots \ldots \ldots \ldots . \ldots \ldots$

Conclusions $\ldots \ldots \ldots \ldots \ldots \ldots \ldots \ldots \ldots \ldots$

Recommendations $\ldots \ldots \ldots \ldots \ldots \ldots \ldots$

Future study $\ldots \ldots \ldots \ldots \ldots \ldots \ldots \ldots$

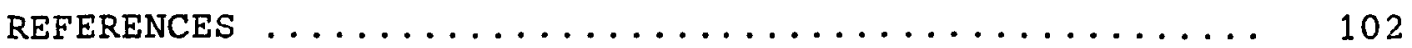

APPENDICES

A TEACHER PERCEPTION SURVEY $\ldots \ldots \ldots \ldots \ldots \ldots$

B LETTER TO ADMINISTRATORS ........... 113 
I Description of Respondent Pool

by School District ..............

II Composition of Participating

School Districts (Elem. Level) .......

II Distribution of Responses to Questions Regarding Techniques for the Teaching

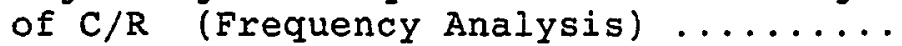

IV Positive Response Percentage to the Clarifying Subquestion: Use of Role play ..................

V Positive Response Percentage to the Clarifying Subquestion: Use of

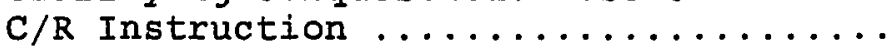

VI Positive Response Percentage to the Clarifying Subquestion: Use of

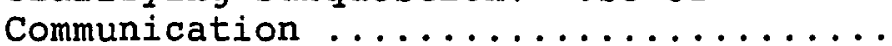

VII Positive Response Percentage to the Clarifying Subquestion: Use of

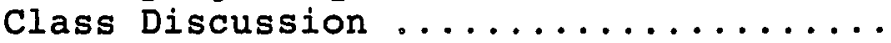

VIII Positive Response Percentage to the Clarifying Subquestion: Use of Various Media ..................

IX Correlations Between Demographic Criteria and Use of Five Techniques For the Teaching of $\mathrm{C} / \mathrm{R} \ldots \ldots \ldots \ldots \ldots \ldots$

$\mathrm{X}$ Comparisons Between the Use of Various Techniques For the Teaching of $\mathrm{C} / \mathrm{R} \ldots .$.

XI Summary of Responses Indicating Use of Various Techniques For the Teaching of $\mathrm{C} / \mathrm{R} \ldots \ldots \ldots \ldots \ldots \ldots \ldots \ldots . \ldots \ldots$ 
viii

XII Differences Between Responses of

Teachers Who Had Staff Development For

the Teaching of $C / R$ and Responses

of Teachers Who Did Not

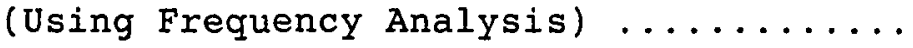

XIII Differences Between Responses of

Teachers Who Had Staff Development For the Teaching of $C / R$ and Responses of Teachers Who Did Not

(Using Chi Square and Phi Test) .......

XIV Positive Response Percentage to the Clarifying Subquestion: Use of

Cooperative Learning .............

XV Differences Between Responses Regarding Cooperative Learning and Responses Regarding Techniques Specifically Designed to Teach $C / R \ldots \ldots \ldots \ldots$ 
AN ABSTRACT OF THE DISSERTATION OF Marcia Gregor Garrick for

the Doctor of Education in Educational Leadership:

Educational Administration and Supervision presented (date)

Title: Elementary Teachers' Perceptions of Their

Instructional styles in the Teaching of Conflict

Resolution.

APPROVED BY THE MEMBERS OF THE DISSERTATION COMMITTEE:

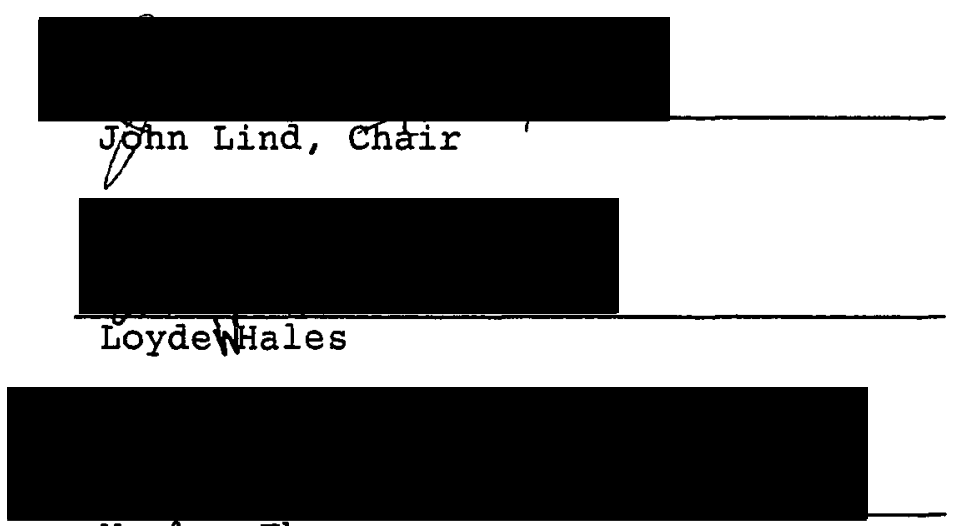

Maxine Thomas

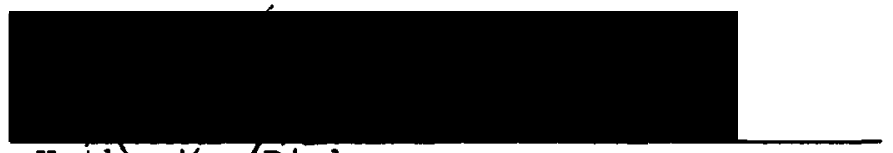

Kathoríne/Dickson

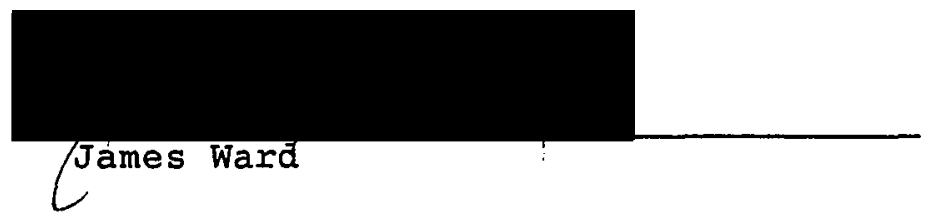

In order to assess current practices in the teaching of conflict resolution, this study examined (through survey methods) the perceptions of teachers in three Oregon school districts of similar size regarding the techniques they use 
to teach conflict resolution skills to their students, teachers' perceptions of the frequency of the use of those techniques, and teachers' perceptions of the effectiveness of those techniques. This study also compared the responses of teachers in school districts which provided teachers with staff development for the teaching of conflict resolution with the responses of those teachers from districts without that staff development. In addition, the survey examined the impact of cooperative learning on the teaching of conflict resolution.

Data were reported in terms of frequency distribution, Spearman Correlation analysis, Chi Square, and Phi

Correlations. The results indicate that elementary teachers use a wide variety of techniques to teach students how to get along with one another. Although they favor certain techniques, they do not use one technique to the exclusion of another.

The hypothesis that demographic criteria may be linked to teachers' responses to the use of certain techniques was also rejected. Comparisons between responses of teachers from districts which supplied staff development for the teaching of conflict resolution and responses from teachers from districts which did not do so are inconclusive. Possible reasons may stem from different but, perhaps, equally enriching programs for the teaching of conflict resolution. 
Cooperative Learning is not primarily used as a method to teach conflict resolution. Those who use it, however, indicated that they saw increased conflict resolution skills as a by-product of that teaching method.

The data gleaned in this survey would indicate that the following be considered when implementing a program for the teaching of conflict resolution: Conflict is a natural state which accompanies change and can act as a constructive force. Conflict in the classroom can provide a creative tension which helps to inspire problem-solving. Wellhandled conflict can have benefits for increasing student motivation and may result in higher achievement and greater understanding of the subject. Conflict itself may prove to be an effective component of specific lessons.

One apparent advantage to teaching appropriate use of conflict resolution is that if students know from their own experience that social relations need not be adversarial and that they can share power without losing influence, children may be better prepared to grow as global citizens. 
CHAPTER I

\section{INTRODUCTION}

\section{STATEMENT OF THE PROBLEM}

The potential for conflict exists when the needs of two or more parties are at odds with one another. Conflict exists when one or more of those parties attempts to fulfill those conflicting needs.

Stories of conflict are recorded daily in newspapers, magazines and television news broadcasts. These conflicts can exist at any social, political or chronological level. Conflicts occur between warring countries, embattled religious leaders, quarreling church personnel and opinionated educators.

Conflict also occurs among a less sophisticated group: children. Classrooms across the world have potential to be miniature battlefields, producing small conflicts among those inhabitants with competing needs.

Managing conflict among elementary students is a crucial and often primary task of elementary school teachers. Classroom conflicts among students can infringe on learning time, taking time from bone fide classroom activities, and focusing the attention of the teacher and the students on disruptive activity. Such disruptions of learning time are a 
major concern to teachers and absorb a significant amount of teacher time (Flad, 1989).

Just as some world leaders handle conflict in a less disruptive, more productive fashion than others, some children are more adept than others in meeting their individual needs without creating a conflict situation. Children handle conflict in a variety of ways, some of which are adverse and exacerbate the difficulty. While some children are able to discuss competing or conflicting needs with their opponents in a way that meets mutual needs, other children may fight either physically or verbally or may become alienated from their classmates and break with longstanding friendships (Dittrich, 1987).

Such classroom conflicts have the potential for disrupting learning by altering the classroom's learning environment. Classroom conflicts have a profound effect on the feeling tone in a classroom before, during and after the time in which they occur, disrupting classroom mood (Kreidler, 1988), and changing the focus from the learning activity to the disruptive behavior.

During a classroom conflict those students not directly involved may, nevertheless, become deeply affected by it. Students may feel compelled to side with friends, neighbors, acquaintances, or relatives. Those divided loyalties can be distracting to all involved and can easily cause additional conflicts which can further infringe on learning time. 
In addition to lost learning time, destructive conflict between children or inability to deal with those conflicts may affect children's ability to maintain friendships. This friendship-relationship strongly affects social development. Children with friends tend to develop higher levels of altruism than those who do not have friends (Nelson \& Aboud, 1985). Development of social relationships is a crucial part of forming the whole child; learning how to handle disagreement is a key part of that education.

Classroom disagreements can become opportunities for teachers to instruct students in the positive aspects of conflict and resolution thereof (Dittrich, 1987). In the hands of an adept teacher, the conflict situation itself can become a starting point to a lesson in which students learn appropriate methods of dealing with controversy and quality methods for creating concurrence. By teaching students the skills to deal appropriately with controversy and create effective, appropriate methods of concurrence, teachers can have a positive effect on students' ability to make effective decisions.

In addition to teaching the skills to create concurrence, there was some evidence to suggest that controversy itself may be used effectively as a learning tool. A lively classroom discussion may spark the interest of apathetic students and provide opportunities for a sense of affiliation with the classroom and the subject itself. 
Using controversy in the classroom may develop higher levels of reasoning, greater curiosity about the subject and greater feelings of personal efficacy (Johnson, Johnson, Smith \& Peterson, 1984). In group learning, controversy may produce a higher liking for the subject matter itself (Johnson \& Johnson, 1984).

Some educators indicate that students have a strong desire to solve conflicts and look for specific ways to settle their disagreements with one another. Students often look to school personnel to assist them in solving those problems (Dittrich, 1987).

Myriad techniques for teaching about conflict and managing it in the classroom exist; those people with the most expertise and experience therein may be the elementary teachers themselves (Kreidler, 1984). Whether or not they have had formal training in conflict resolution, due to the immediacy of those situations, teachers are often compelled to handle such conflicts within the confines of the classroom.

PURPOSE OF THE STUDY

The purpose of this study was as follows: To examine elementary teachers' perceptions of the techniques they use to teach conflict resolution skills; to examine teachers' perceptions of frequency of use of those techniques; to 
examine teachers' perceptions of the effectiveness of these techniques.

By collecting and synthesizing elementary teachers' self-report of their techniques of teaching conflict resolution, it was the purpose of this research to create new knowledge in the area of Conflict Resolution Education.

SIGNIFICANCE OF THE STUDY

This study examines teachers' self-perceptions of the manner in which elementary teachers teach conflict resolution skills to their students. In order to examine the impact of the teaching of those skills it was important to examine current practices.

This study examined the aforementioned practices in three school districts as well as teachers' perceptions of the frequency and effectiveness of the use of those techniques. In doing so, this research creates a benchmark for further study of the teaching of conflict resolution in the elementary classroom.

Educators are a powerful directing force in teaching children to get along with one another. By creating a social environment in which students know from their own experiences that social relations need not be adversarial and that they can share power without losing influence, children are better prepared to grow as global citizens (Lodato, 1982). 
RESEARCH QUESTIONS

\section{Primary Questions}

1. What are teachers' perceptions of the techniques used to teach conflict resolution skills to elementary students?

2. What are teachers' perceptions of the frequency of the use of those techniques?

3. What are teachers' perceptions of the effectiveness of those techniques?

\section{Secondary Questions}

4. Is there a significant difference between the responses of teachers from districts which provided related staff development and those teachers from districts who did not provide that staff development?

5. What are teachers' perceptions of the effectiveness of cooperative learning as a technique for teacher conflict resolution skills?

\section{ASSUMPTIONS}

The following assumptions were made in this study:

1. Teachers accurately reported their perceptions on the survey instrument.

2. All surveys were distributed and administered in a consistent manner. 
3. Returned surveys represent the perceptions of teachers in the three districts in which they survey was administered.

\section{LIMITATIONS OF THE STUDY}

This study has the limitation in that the data are self-reporting.

Fifty-four percent of the teachers to whom the study was distributed chose to complete and return the survey. Only 31 percent of the elementary teachers from West Iinn chose to complete and return the survey, while Newberg's response was 85 percent and McMinnville's 46 percent.

The data collected are specific to teachers in the school districts chosen. They do not necessarily represent the perceptions of teachers from districts of significantly different socioeconomic or geographic background.

This study utilized descriptive research in which cause and effect are not established.

\section{ORGANIZATION OF THE DOCUMENT}

This dissertation is divided into five chapters. Chapter I introduces the problem and provides an overview of the study. In addition, it includes the purpose and significance of the study, research questions, assumptions, limitations and organization of the study report. 
Chapter II includes a review of the literature on conflict resolution in the educational setting.

Chapter III explains the methodology and procedures

used to study the research problems. It also includes a

description of the subjects and their districts.

Chapter IV reports the findings of the analysis of the data collected.

Chapter $V$ presents the findings and conclusions of the study, describes limitations, makes recommendations, and offers suggestions for further areas of study and research. 


\section{CHAPTER II}

IITERATURE REVIEW

A survey of the literature related to the topic of this study was conducted. The survey included computer searches of Educational Resources Information Center (ERIC), research information from Center for Peace Learning at George Fox College, information collected at Mediation Project in Amherst, Massachusetts and the Harvard Mediation Project.

OVERVIEW OF LITERATURE

Johnson and Johnson (1979, 1985, 1986) developed a theory concerning the process by which controversy can promote a positive outcome. The authors state that teachers tend to be afraid of controversy and to quiet it in their classrooms. Evidence indicates that teachers avoid or suppress conflict among students, assuming that such conflicts will create dislike and resentment and alienate students from one another and that less capable individuals will be defeated or humiliated. Doing so may not, however, be the most effective means of resolving conflict (Dececco \& Richards, 1974). 
Others believe that well-handled conflict can have tremendous benefits for increasing student motivation, giving a more accurate understanding of different perspectives, higher achievement and greater enjoyment of the instructional experience (Deutsch, 1973; Johnson, 1979, 1980; Johnson \& F. Johnson, 1982; Johnson \& R. Johnson, $1979,1985)$.

Involving students in controversial discussions is one of the least used strategies in teaching (Johnson \& Johnson, 1986). Educators appear to be uncomfortable with the presence of academic conflict in their classrooms because they do not have a clear instructional model that allows them control over that conflict. The authors propose a process by which controversy promotes positive outcomes. They suggest the following strategies and assumptions:

1. Learning begins with students organizing and categorizing present information and experiences so that conclusions can be derived.

2. Students' views are challenged by other students who present opposing points of view.

3. Students experience conflict and uncertainty when they are challenged by conclusions that are incompatible with their conceptual framework. 
4. Students experience curiosity and actively search for more information and experiences to validate their positions.

5. Students actively advocate their position and seek to understand the opposing position and supporting rationale.

6. The quality of students' synthesis depends on the quality with which they have followed the aforementioned steps.

The authors conclude that: a) controversy results in greater mastery and retention of the subject being learned; b) controversy results in high quality decisions and solutions to problems; c) controversy promotes creative insight.

Davis and Porter (1985) describe conflict as a natural human state which often accompanies institutional change or personal growth and can act as a constructive force when approached appropriately. The authors state that children are not truly educated unless they are prepared to deal with the disquieting. More effective methods than those that are currently in practice are necessary to deal with conflict in the school setting. The authors believe that the use of mediation to solve school-based disputes can improve communications and school climate and reduce inappropriate behavior among students. 
Davis and Porter's (1985) vision of mediation training emphasizes listening to others' points of view and resolving differences peacefully.

Some literature indicates legitimacy in the study of the conflict among children and the varying strategies for resolving that conflict. Schmuck (1986) differentiates between differing styles of conflict and appropriate management strategies. Schmuck and Schmuck (1988) state that conflict itself, for many people, carries a negative, emotional loading and that the word has been given connotations which are mostly negative due to tension, anxiety and unpleasantness that often arises in conflict situations. The authors believe, however, that conflict in the classroom can provide a creative tension which helps to inspire problem-solving and improve individual or group performance. They believe that conflict can mature the relationship between the parties who are in disagreement. McGinnis and Delberg (1988) state that children imitate their parents' attitude and values toward conflict from infancy and that even pre-school aged children can successfully participate in and learn from conflict resolution strategies.

Throughout the literature, empathy and accompanying knowledge of what to do with that empathy is suggested as a key ingredient for the actual resolution of conflict among school children. Ayers (1976) suggests that understanding 
and respecting the differences of others alleviated conflict among school children. Bernman and Meil (1983) argue that students participating in cross-cultural experiences encounter cooperation and empathy for the values of others. Clair (1983) goes so far as to state that such empathy has potential for reducing world conflict.

The majority of the citations became available as a result of searches related to conflict resolution and peace education. The recent literature in conflict resolution instruction indicates a wide variety of techniques for solving classroom conflicts. Conflict resolution instruction literature tended to group techniques for teaching conflict resolution in the classroom into five occasionally overlapping approaches to teaching and treating conflict in the classrooms:

1. Role Plays. Role plays are activities in which participants act out the persona of a specific character. In role playing for the purpose of teaching conflict resolution these characters are chosen to demonstrate a specific conflict problem of or a skill or technique for solving a problem.

2. Instruction in Conflict Resolution. Teachers instruct students in the theory, practice and techniques for resolving conflicts. 
3. Communication Techniques. Teachers instruct students in communication skills for the specific purpose of explaining conflict resolution. Students learn about and how to use appropriate language for this task.

4. Classroom Discussion. Teachers direct students to talk to one another in groups of varying sizes. They are instructed in the techniques of group discussion and use those discussions to work together to talk about or solve conflict.

5. Drama and Art. Teachers direct students to participate in various media for the purpose of teaching specific conflict resolution skills.

\section{ROLE PLAYS}

Dunn (1988) suggests that role plays are significant tools for learning about conflict and suggests specific techniques for the process. A successful negotiator, Ron Mock (1988), states that the role play is a powerful tool for students to learn new interpersonal skills and strongly suggests that the role play is irreplaceable in practicing new ideas, attitudes and approaches to dealing with conflict.

Meredith (1987) quotes conversations with Thomas Lickona who uses role playing among pre-schoolers with the teacher acting the part of one of the disputants. Through role play the teacher illustrates the manner in which 
conflicts begin and can be solved. Meredith disputes Piaget who believed that young children are too egocentric to understand one another's feelings. Her research indicates that young children can, in fact, understand the feelings of others; conflict can be avoided if adults intervene before children become to emotionally involved in a dispute and when adults' direction is clear and age appropriate.

\section{INSTRUCTION IN CONFLICT RESOLUTION}

Olivero (1979) suggests school climate improvement through the use of problem solving skills. Perhaps the most significant literature on problem solving skills in conflict resolution, albeit from the business world, comes from the 1981 work Getting to Yes by Fischer and Ury from the Harvard Negotiation Project. This works delineates four steps for successful negotiation, steps which are often used in problem solving and teaching about classroom conflict.

Ury and Fischer (1981) suggest that all human beings, whether they like it or not, are negotiators. The authors suggest that successful negotiators use neither "hard" or "soft" negotiation but instead use "principled negotiation" through which one obtains what one is entitled to while still remaining decent. 
Fischer and Ury (1981) state that any negotiation can be deemed successful if the following occur:

1. If agreement is reached, it should be a wise agreement.

2. The process should be efficient.

3. The process should improve or at least not damage the relationship between the parties.

The authors indicate that arguing over specific positions is inefficient. In positional bargaining negotiators tend to lock themselves into their positions. More attention needs to be paid to the underlying concerns of the parties and less to their positions. Arguing over positions also endangers ongoing relationships. If there are more than two parties, positional bargaining can be extremely difficult. Caution should also be made to refrain from the compliant to obtain agreement and focusing on the necessity of reaching agreement.

In principled negotiation the above concerns are avoided by the following strategies:

1. Separate the people from the problem.

Emotions often become entangled with the objective merits of the problem. When people "take positions" their egos become identified with the positions. Participants should instead come to see themselves working side-by-side. 
2. Focus on interests instead of positions.

Focusing on a negotiating position can obscure needs of individual participants. Compromising between positions does not produce an agreement which will take care of the human need involved.

3. Invent options for mutual gain.

Setting aside a time in which participants list mutually acceptable options responds to the difficulty of designing quality solutions in a pressure situation.

4. Insist on using objective criteria.

In positional bargaining, issues are often decided on the basis of will, a costly way to determine outcome. Concentrating on the merits of the problem by approaching agreement through the discussion of objective criteria, according to the authors, produces wise (and lasting) agreements amicably and efficiently.

Ury and Fischer suggest that all human beings, notwithstanding their age or life role, act as negotiators on a regular basis.

\section{COMMUNICATION TECHNIQUES}

Iincoln (Nebraska) School District's "Communication Skills Curriculum" (1982) includes as part of its premise that good communication is crucial for conflict resolution. Teachers Schmidt and Friedman (1983) wrote of their use of appropriate communication ("I care language") to teach 
conflict resolution in the classroom. The authors state that it takes practice for students to learn to express needs, rights and feelings in a way that is honest, direct and non-threatening, but feel that the time spent on such lessons is crucial. Students are directed to:

1. Address opponent directly. Use the other person's name as a sign of respect.

2. State feelings. Show how the other person's action affected you.

3. Identify problems. Avoid focusing on blame, excuses or personal attacks.

4. Offer a solution. Begin brainstorming ideas for mutual gain.

5. Make lists of "fouls" or destructive behavior such as name calling, etc. and avoid such destructive behaviors.

Teachers are to direct students to be aware of the merits of using appropriate language to fighting fairly.

Fry (1986) argues that instruction in communication is a "likely forum for the management of conflict". Meredith (1987) suggests the use of thoughtful, constructive communication, what shure and Spivak (1987) call "interpersonal problem-solving communications". This type of communication stresses that children describe feelings, motivation and outcomes. This process is child centered and empowers children to have some control over their 
surroundings. The opposing method would be for the adult to direct students to "get along" or "share" ambiguous words to youngsters.

CLASSROOM DISCUSSION

Edleson (1981) states that an effective response to conflict can be defined as one that:

1. reduces the problems encountered in a particular situation;

2. produces positive consequences;

3. minimizes negative consequences.

He states that group discussion is an effective way to deal with conflict and offers several advantages for that technique:

1. Groups enable members to interact with peers.

2. A group format, as compared to a one-to-one training format, offers a wider variety of models and feedback.

3. The participation of peers should, by increasing the similarity between the group environment and the child's real world's, increase the probability that learned skills will be used in situations outside the group.

4. Group discussion is far more attractive to students than one-to-one training.

Edleson (1981) suggests ways in which classroom discussion may be used to teach students successful ways to 
resolve conflicts with peers. He describes a group approach to training students to work with one another and stresses group discussions. The author believes that students must be trained to work together in groups and do not begin solving interpersonal conflicts until that training has taken place.

Munnely (1971) has specific suggestions for the teacher during a classroom discussion surrounding conflict. He states that the teacher acts as a facilitator of learning. The children themselves will be active as they discuss the situation: ordering, classifying, questioning, inferring, and guessing. The teacher must help students to formulate questions, but not to create the questions for them. Productive solutions depend on well constructed questions and it is the teacher who has the responsibility to direct such questioning. Most important, teachers should encourage friendly and constructive criticism as being welcomed.

Crary (1986) suggests that during a discussion involving conflict, adults follow several steps to facilitate problem solving:

1. Encourage solutions where everyone wins. By helping children focus on people's feelings a win-win result is more likely to occur.

2. Avoid criticizing students' ideas. Instead, assist students in learning to evaluate their own ideas. 
If children continue to jive argumentative or inappropriate ideas focus on generating more ideas rather than critiquing those given.

3. Focus on children's ideas. Adults should not offer their own ideas while leading a class discussion. Doing so will cause children to assume that adults' ideas are better than their own.

4. Review the problem frequently. It is easy for children to become distracted from the problem. Continue to direct children's focus on the original problem.

5. Act as blackboard. Children have difficulty remembering ideas. When adults keep track of ideas, children can focus on generating options.

6. Focus on content, not grammar. Ignore poorly structured sentences. When one summarizes children's ideas restructure them grammatically without focusing on the grammar itself.

Most importantly, Cary directs adults to respect children's feelings.

\section{DRAMA, LITERATURE AND ART}

Schmidt and Freidman (1983) describe the way in which they use student art projects to teach conflict resolution strategies in the classroom. They begin with the premise that studying conflict is important because most people spend a great deal of time and energy in conflict. 
Although it is not possible to eliminate conflict the authors feel that it is possible to deal with it in a thoughtful and just manner. In the authors' program students learn the causes of conflict and the consequences when conflict is ignored. Students explore ways to resolve conflict in a positive manner.

The authors direct students to see conflict and associated feelings through a variety of ways using art, drama and writing projects to explore these issues. The authors are particularly careful to illustrate the damage caused by "fouls" or destructive behavior such as name calling and blaming.

Aside from art activities, teachers using this program are directed to role model appropriate behaviors and role play inappropriate behaviors.

Meredith (1987) states that poor peer relations in early years will only exacerbate as years progress. She suggests a variety of puppetry techniques that can be used by classroom teachers to teach conflict resolution.

Leyser and Wood (1980) discuss the use of conflict interventions through the use of puppetry and give detailed evaluation procedures for those interventions, stressing the importance of evaluation. The authors state that clinicians and counselors often get better insight into situations of conflict by watching children interact with puppets. They state that the classroom teachers can better 
understand children's ideas and feelings by watching them manipulate puppets.

After describing the significance of the use of puppetry in working with children in conflict situations, the authors describe a systematic approach to evaluating the effectiveness of a puppet intervention. The step-bystep approach was as follows:

1. Defining the behaviors to be changed.

2. Observing and counting the frequency of those behaviors.

3. Designing the puppet intervention.

4. Implementing the intervention.

5. Observing and counting the frequencies of the behaviors at the end of the program.

The authors indicate that an important outcome of the project was that teachers were able to expand their role. The elementary teachers involved in this project were quite capable of acting as researchers in their classrooms.

Pirtle (1984) describes activities designed to teach peace education through conflict resolution. The author's work underscores the fact that education in conflict resolution has many strands:

1. Cooperation

2. Studying local community leaders

3. Studying the work of famous peacemakers

4. Encountering people who are different from you 
5. Making decisions

6. Learning about change

7. Looking toward the future

Pirtle (1984) describes ways in which teachers can direct students in a variety of activities to teach conflict resolution, including art activities to promote cooperation, examining conflict itself through the use of art and role playing, or drama and studying role modeling methods in the teaching of conflict resolution techniques where students act out the part of famous peacemakers. She stresses the arts as an entryway because they are concrete mediums for exploring theoretical concepts. She states that such activities provides "containers or nets for a child to catch hold of and examine new ideas and through the interacting with the materials develop understanding."

Educators have also found that games can be an effective method of drawing out and dealing with conflict (Berg \& Marlowe, 1974; Schmidt \& Friedman, 1987). Berg and Marlowe (1974) created gaming strategies for use with elementary students in the teaching of decision making in conflict situations. Schmidt and Friedman (1987) designed gaming strategies for using conflict productively in the classroom. 


\section{SUMMARY}

A review of the literature indicates a need for research to determine which techniques for teaching conflict management are used most in elementary classrooms and which of these methods are the most effective. This research will attempt to determine which methods teachers perceive that they used and which they indicate are effective.

The assessment study intended for this research will be a teacher perception survey. Likert (1961) pioneered the perception survey in 1961 with his work with organizational management. "The survey process begins with the administration of questionnaires to members of an organization...The questionnaires are tabulated and the results are computed." (Bolman \& Deal, 1987) According to Likert, after the next step is the interview and the subsequent analysis. Such a follow-up study would be appropriate for further research. 


\section{CHAPTER III}

\section{METHODOLOGY}

This chapter describes the methods and procedures used to investigate teachers' perceptions of the manner in which they teach conflict resolution in their classrooms. After a review of the literature, six areas were chosen to be investigated. They are: a) role play, b) instruction in conflict resolution techniques, c) communication techniques for teaching conflict resolution, d) the use of class discussion in teaching conflict resolution, e) other media in the teaching of conflict resolution, and $f$ ) the effectiveness of cooperative learning as a means of teaching conflict resolution.

The topics of discussion included in this chapter are: Method of research, statistical hypothesis, description of the school districts, description of the respondents, the instrument, data collection, and data analysis.

\section{METHOD OF RESEARCH}

This study was designed to obtain data as follows:

1. To examine the perceptions of teachers regarding the techniques in which they teach conflict resolution to their elementary students. 
2. To examine elementary teachers' perceptions of the frequency of the use of those techniques.

3. To examine teachers' perceptions of the effectiveness of those techniques.

The researcher examined the perceptions of elementary teachers regarding the techniques they use to teach conflict resolution skills, teachers' perceptions of the frequency of the use of those techniques and teachers' perceptions of the effectiveness of those techniques.

This study then developed generalizations regarding the manner in which teachers perceive that they instruct students in conflict resolution skills. Statictical analyses were conducted to determine if there was any significant relationship between demographic criteria (numbe= of years in teaching, grade level taught) and responses to the questions on the survey instrument. Further tests determined relationships between responses to the forty-seven questions on the survey instrument.

Best and Kahn (1986) indicate that descriptive statistical analysis limits generalizations to the particular group of individuals observed. No conclusions are extended beyond this group, and any similarity to those outside the group cannot be assumed. The data collected in this survey form a descriptive analysis and provide information about respondents from the three school districts surveyed. 
A survey research method was used to answer the research questions used in this study. This method allowed the researcher to gather data from six school districts in a similar time frame.

\section{STATISTICAL HYPOTHESES}

The null hypotheses tested in this study were as follows :

1. There is no significant relationships between the responses of:

a. The teachers who state they use role play to teach conflict resolution and the teachers who state that they instruct students in conflict resolution techniques.

b. The teachers who use role play to teach conflict resolution and the teachers who state they use specific communication techniques for the purpose of teaching conflict resolution.

c. The teachers who state that they use role play to teach conflict resolution and the teachers who state that they use classroom discussion to teach conflict resolution techniques.

d. The teachers who state that they use role play to teach conflict resolution and the teachers who state they use various media to teach conflict resolution skills. 
e. The teachers who state that they instruct their students in conflict resolution techniques and the teachers who state they teach communication skills for the purpose of teaching conflict resolution.

f. The teachers who state that they instruct their students in conflict resolution techniques and the teachers who state they use classroom discussion to teach conflict resolution skills.

g. The teachers who state that they instruct their students in conflict resolution and the teachers who state they use various media to teach conflict resolution techniques.

h. The teachers who state that they teach communication skills for the purpose of teaching conflict resolution and the teachers who state they use classroom discussion to teach conflict resolution techniques.

i. The teachers who state that they teach communication skills for the purpose of teaching conflict resolution and the teachers who state they use various media to teach conflict resolution skills.

j. The teachers who state that they teach conflict resolution skills and the teachers who state they use various media in the teaching of conflict resolution skills. 
2. There is no significant relationship between demographic criteria and responses to the survey questions.

3. There is no significant relationship between the responses of teachers in a district which had been exposed to staff development regarding the teaching of conflict resolution and teachers from districts who had not been exposed to that staff development.

\section{SCHOOL DISTRICTS}

This study surveyed three Oregon districts similar in size: Newberg, McMinnville and West Linn. The questionnaire respondents are reflected in Table I (Description of Respondent Pool by School District).

TABLE I

DESCRIPTION OF RESPONDENT POOL BY SCHOOL DISTRICT

\begin{tabular}{lll}
\hline District & Count & Percentage \\
\hline Newberg & 60 & 45.802 \\
McMinnville & 37 & 28.244 \\
West Linn & 34 & 25.954 \\
\hline
\end{tabular}

Takle I presents the distribution of total pool of respondersts, showing the percentage of those respondents accross eavh district. The respondent pool consisted of three school district: West Linn, Newberg and McMinnville. The largest percentage of participants represented in the 
total respondent pool was from Newberg School District, which represented 46 percent of the total pool. The smallest percentage of participants represented in the respondent pool was from West Linn representing 26 percent.

The return rate or percentage of teachers who received the survey and chose to respond varied from district to district. The return rate in West Linn was 31 percent; in Newberg the return rate was 85 percent; McMinnville return rate was 46 percent. The return rate of the total pool of teachers was 54 percent.

The respondents' years of teaching experience (number of years in teaching) ranged in years from one to thirty-seven. The three participating school districts were of similar size but varied somewhat in composition. All three school districts are located within commuting distance of Portland, Oregon -- a metropolitan city of just under 400,000 residents. Many of the residents of West Linn, Newberg and McMinnville commute daily to Portland, but each of the smaller cities is a community with separate and distinct identities.

West Linn is a city of 13,000 residents. Although the majority of residents who are employed commute to Portland, a large paper manufacturer employs many residents. Most of the students from West Linn School district are from the confines of the city, but a significant percentage is from the surrounding rural areas. Its school district serves 
approximately 4,300 students in four elementary schools, three intermediate schools and one high school. Students score above the state and national averages on standardized tests. The district's average teacher/student ratio is $1: 22$. The school district enjoys a strong reputation for community support through financial support and community involvement. Newberg is a city of approximately 12,000 residents. Although many of Newberg's residents are commuters, a variety of businesses employ a large percentage of the population in industries, including wineries, a large dental equipment manufacturer and a major paper producer. Newberg School District serves students from the confines of the city but a large percentage is from the surrounding rural areas. The school district serves approximately 4,100 students in five elementary schools, two intermediate schools and one high school. Students score above the state and national averages on standardized tests. The district's average teacher/ student ratio is $1: 22$.

McMinnville is the county seat of Yamhill County. Of the three cities, McMinnville is probably the least influenced by its proximity to Portland. Although many residents commute to Portland, Newberg or Salem, McMinnville's light industry employs a large portion of its working population. McMinnville is a city of 16,000 residents. McMinnville School District serves students from the confines of the city, but a large percentage is from the 
surrounding rural areas. The school district serves approximately 4,000 students in six elementary schools, one intermediate school and one high school. One of the elementary schocls serves the residents of the small town of Lafayette, a city which does not have its own school district. Students score above the state and national averages on standardized tests. The district's average teacher/student ratio is $1: 25$.

Table II illustrates the composition of the elementary portion of each participating school district.

The elementary teachers in three school districts of similar size were selected to report on their perceptions regarding the techniques they used to teach conflict management in their classrooms. "Elementary teacher" is defined as one who teaches students in grades Kindergarten through Five.

TABLE II

COMPOSITION OF PARTICIPATING SCHOOL DISTRICTS (ELEMENTARY LEVEL)

\begin{tabular}{lcccc}
\hline $\begin{array}{l}\text { District/ } \\
\text { School }\end{array}$ & $\begin{array}{c}\text { Student } \\
\text { Population }\end{array}$ & $\begin{array}{c}\text { Teacher } \\
\text { Population }\end{array}$ & $\begin{array}{c}\text { Teacher } \\
\text { Range } \\
\text { Range }\end{array}$ & $\begin{array}{c}\text { *C.R. } \\
\text { Training } \\
\text { Provided }\end{array}$ \\
\hline Newberg & 1,716 & 70 & B.A. - M.A. & NO \\
McMinnville & 1,978 & 80 & B.A. - M.A. & NO \\
West Linn & 2,135 & 110 & B.A.- M.A. & YES \\
\hline
\end{tabular}

* C.R. = Conflict Resolution 
All of the districts' personnel offices provided information on number of elementary teachers. All teachers were invited to respond. Each elementary teacher in each district was asked to complete a survey where they reported which techniques they used to teach conflict resolution skills to students in their classrooms. The surveys were distributed by mail, with placement in individual teachers' school mail boxes. A cover letter was attached to each survey, providing directions for survey completion. Survey collection occurred when respondents placed completed surveys in collection envelopes (placed in each school's main office). The return of the survey signified the respondent's participation consent.

\section{THE SURVEY INSTRUMENT}

One questionnaire (see Appendix A) was developed for use in this study. It consisted of 70 items that the review of literature indicated (Chapter II) were either techniques for the teaching of conflict resolution in the classroom or requests for appropriate demographic information. Forty-seven nondemographic information items were grouped into five approaches to teaching conflict resolution to elementary students and one teaching technique which may or may not have an impact on the learning of conflict resolution skills.

The survey was designed for all elementary teachers in the three specific districts and asked each respondent to choose a value rating for each of the listed items by indicating their 
rating on a scale provided after each item. The Teacher Perception Survey was designed by the researcher to determine teachers' perceptions of the manner in which they teach conflict resolution to elementary school students. Answers were indicated by using a likert scale with "1" representing strong disagreement with the statement, "2" representing mild disagreement with the statement, "3" representing mild agreement with the statement and "4" representing strong agreement with the statement. Responses in an additional column with an empty box indicated that the question was not applicable to the respondent.

The body of the questionnaire was divided into six sections, five of which were related to specific techniques that teachers might use in teaching conflict resolution to their elementary school students. The sixth section was devoted to questions about cooperative learning, a teaching technique which may or may not have an effect on participating students in regard to the manner which they approach resolution of conflict. Questions in this section were devoted to the manner in which teachers perceived that participating students resolved conflict.

Each of the five techniques' questions was enhanced by seven clarifying subquestions. The purpose of these subquestions was to gain information on teachers' perceptions of how they taught those five specific techniques. The seven subquestions contained five questions which expanded upon the 
manner in which a particular technique was taught. Next was a frequency of use question followed by an effectiveness question. After each main section space was provided for additional comments and lists of resources. A space was also provided after each question and each subquestion for comment. The six areas questioned were as follows:

1. Role Play: The purpose of this set of questions was to determine teachers' perceptions of the use of role play to teach conflict resolution, their perceptions of the frequency of that use, as well as their perceptions of the effectiveness of that technique.

2. Conflict Resolution Instruction: The purpose of this set of questions was to determine teachers' use of conflict resolution instruction, their perceptions of the frequency of that use, as well as their perceptions of the effectiveness of that technique.

3. Communication: The purpose of this set of questions was to determine teachers' perceptions of the use of teaching communication techniques for the purpose of teaching conflict resolution, their perceptions of the frequency of that use, as well as their perceptions of the effectiveness of that technique.

4. Class Discussion: The purpose of this set of questions was to determine teachers' perceptions of the use of class discussion to teach conflict resolution, their perceptions 
of the frequency of that use, as well as their perceptions of the effectiveness of that technique.

5. Various Media: (Arts/Literature/Drama) The purpose of this set of questions was to determine teachers' perceptions of their use of art, literature and/or arama to teach conflict resolution, their perceptions of the frequency of that use, as well as their perceptions of the effectiveness of that technique.

6. Cooperative Learning: Cooperative learning is not primarily used as a method of teaching conflict resolution. Those who use it, however, may or may not see indirect results with students who work with one another in regard to the manner in which they resolve conflict. The purpose of this set of questions was to determine teachers' perceptions of the manner in which cooperative learning affected students' ability to work with one another.

During all stages of questionnaire development attention was given to questionnaire design criteria suggested by Elliott (1954):

1. The questionnaire must meet certain standards of mechanical correctness: a) neatly produced, b) plenty of space for responses, c) name and address of the investigator and, d) enough information about respondents to facilitate follow-up work;

2. Directions must be complete and clearly stated and be placed close to the point of application;

3. Use only questions which apply to the respondent's situation; 
4. Trivial and irrelevant questions must be weeded out;

5. Ask questions of opinion only when it is opinion one is seeking and the opinion is worth getting;

6. Questions must be simply and clearly stated;

7. Make the response simple, thus requiring the minimum of writing;

8. Give opportunity for the respondents to add items ;

9. Make the questionnaire as short as possible;

10. Responses should lend themselves to easy tabulation;

11. Ask only for information which is not obtainable from documentary sources;

12. The questionnaire should be accompanied by a letter of transmittal;

13. There must be a careful selection of the group to which the questionnaire is to be sent;

14. Include a stamped, self-addressed envelope for return (researcher deviated from \#14 by using personal collection);

15. Try out the questionnaire several times, revising as you go;

16. Offer a summary of the findings (pp. 39-41).

Aside from Number 14, all criteria of this list were met during the development of the questionnaire used in this study. The questionnaire was brought before an accomplished researcher, revisions were made and then brought before the dissertation committee. More revisions were made and the survey was field tested, using input from various elementary teachers. Multiple revisions were instituted as a result of various input prior to 
final draft development. This input included information gleaned from a field test conducted with several elementary teachers from the researcher's own district (Newberg), as well as comments from dissertation committee members.

\section{DATA COLLECTION}

Permission to conduct the was obtained from appropriate personnel in each district. Permission was first granted by personnel directors, then by individual building principals. Each building principal used a memo or weekly announcement to inform teachers that the surveys would be arriving in faculty mail boxes.

Conditions for approval included willingness on the part of the researcher to share findings with individual schools requesting that inservice. Agreement was made to share the results of the survey with those schools requesting such information after completion of the dissertation.

The Portland State University Human Subjects Research Review Committee waived the application and full review of this research.

The cover letter was included on the first page of the survey. It gave specific directions for survey completion, the purpose of the survey, a place for teachers to indicate their request for survey results, as well as a place for demographic information. 
All building principals had been informed of the day in which surveys were to be distributed and each principal had notified staff members of this date, encouraging support. No teachers were compelled to complete the survey.

The researcher or her representative placed an envelope containing the survey instrument and a small note pad in the teachers' mail boxes. The note pad was marked with a graphic design and personalized with the names of the respondents' school district. The surveys, note pads, and envelopes were all professionally printed to indicate the importance of the study. The purpose of the note pad was to encourage teacher interest and participation. The envelope was marked "Conflict Resolution Survey" and listed the researcher's name and city. A copy of the survey is found in Appendix A.

All subjects were asked to respond to the Spring, 1989 questionnaire by a specific date printed on the collection envelopes. These mailings resulted in 131 responses from 54 percent of the teachers to whom the survey was distributed.

The researcher or her representative collected the survey instruments from the main office of each school.

\section{DATA ANALYSIS}

The data collected on the Teacher Perception Survey are summarized and analyzed in Chapter IV in four forms: a frequency distribution, a correlation analysis, a Chi square and a phi test. 
The frequency distribution summary reports the percentage of all respondents selecting a given response for each of the 47 non-demographic items on the questionnaire.

The Spearman Coefficient of Correlation was computed to examine the relationships between the demographic information and response items. Null hypotheses were tested at the .05 level of significance. The following guidelines were used in interpreting the calculated coefficient. A high absolute value suggests a strong relationship between two variables, whereas a near zero value suggests a weak relationship. Best and Kahn (1986) suggest the following as a method for evaluating the magnitude of a relationship:

$$
\begin{aligned}
& \text { Coefficient }(r) \\
& .00 \text { to } .20 \\
& .20 \text { to } .40 \\
& .40 \text { to } .60 \\
& .60 \text { to } .80 \\
& .80 \text { to } 1.00
\end{aligned}
$$

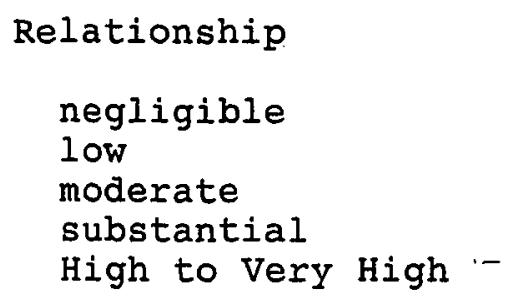

The Chi square is not used as a measurement of correlations. It was, however, computed to determine the likelihood that some factor other than chance accounted for any apparent relationship between the responses of the five techniques for teaching conflict resolution. For each pairing of the major techniques, the null hypothesis that the variables are independent was tested. Since, with the rejection of the null hypothesis, the research hypothesis that the variables are not independent would be accepted, the Chi Square can be seen as 
evaluating the probability that the apparent relationship results from chance.

To determine the actual relationship among the major responses, however, it was necessary to select a test which was able to deal with scores that are 0 and 1 . Hayes (1943) indicates that the "coefficient phi may be regarded as a correlation between attributes $A$ and $B$ when the categories are associated with 'scores' of 0 and 1." In analysis of this study, response 1 (Strongly Disagree) and 2 (Disagree) were compacted to score as a 0 . The response 3 (Agree) and 4 (Strongly Agree) were compacted to score as a 1. The response 5 (Not Applicable) was discounted. For this reason the Phi test was conducted to determine the relationship between various response items.

Best and Kahn's (1986) method for determining the magnitude of a correlation for the Spearman test may be applied to the Phi test. This same method was used in determining the strength of phi. Null hypotheses were tested at the .05 level of significance. 
CHAPTER IV

\section{PRESENTATION AND ANALYSIS OF DATA}

\section{INTRODUCTION}

The purpose of this study was to provide descriptive data which examines teachers' perceptions of the manner in which they teach conflict resolution skills. This chapter reports teachers' responses to the Teacher Perception Survey and furnishes evidence to accept or reject the research hypotheses in Chapter 1 . The data presentation is organized in such a manner as to answer the five research questions: 1. What are teachers' perceptions of the techniques used to teach conflict resolution skills to elementary students?

2. What are teachers' perceptions of the frequency of the use of those techniques?

3. What are teachers' perceptions of the effectiveness of those techniques?

4. Is there a significant difference between the responses of teachers from districts which provide related staff development and those teachers from districts which did not provide that staff development? 
5. What are teachers' perceptions of the effectiveness of cooperative learning as a technique for teaching conflict resolution skills?

The following sections are included in this chapter: a) teachers' perceptions regarding the techniques they use to teach conflict resolution skills to their students, b) a comparison of the responses of teachers from districts which provide related staff development and the responses of teachers from district which did not provide that training, c) teachers' perceptions of cooperative learning as a technique for the teaching of conflict resolution skills, and d) summary of results.

\section{TEACHER PERCEPTION - TEACHING CONFLICT RESOLUTION SKILLS}

The responses to the statements in the Teacher Perception Survey pertaining to the five major techniques for teaching conflict resolution are presented in Table III. First to be examined is the extent of teacher agreement to statements that they use various techniques. Then, for each technique individually, responses to the seven clarifying subquestions are examined for those teachers who indicated that they used the technique. Strong or mild agreement indicated that they used the technique. Strong or mild disagreement indicated that they did not. 
A frequency analysis is first organized to display the distribution of teacher responses to major questionnaire items. This summary of questionnaire response distribution is reported in Table III. The distribution of responses for each major item on the Teacher Perception Survey reports the percentage of respondents selecting a positive or negative response. Their use of various techniques ranged from 46 percent (SA - A) for various media to 77 percent for Use of Role Play.

TABLE III

DISTRIBUTION OF RESPONSES TO QUESTIONS REGARDING TECHNIQUES FOR THE TEACHING OF $\mathrm{C} / \mathrm{R}$ (FREQUENCY ANALYSIS)

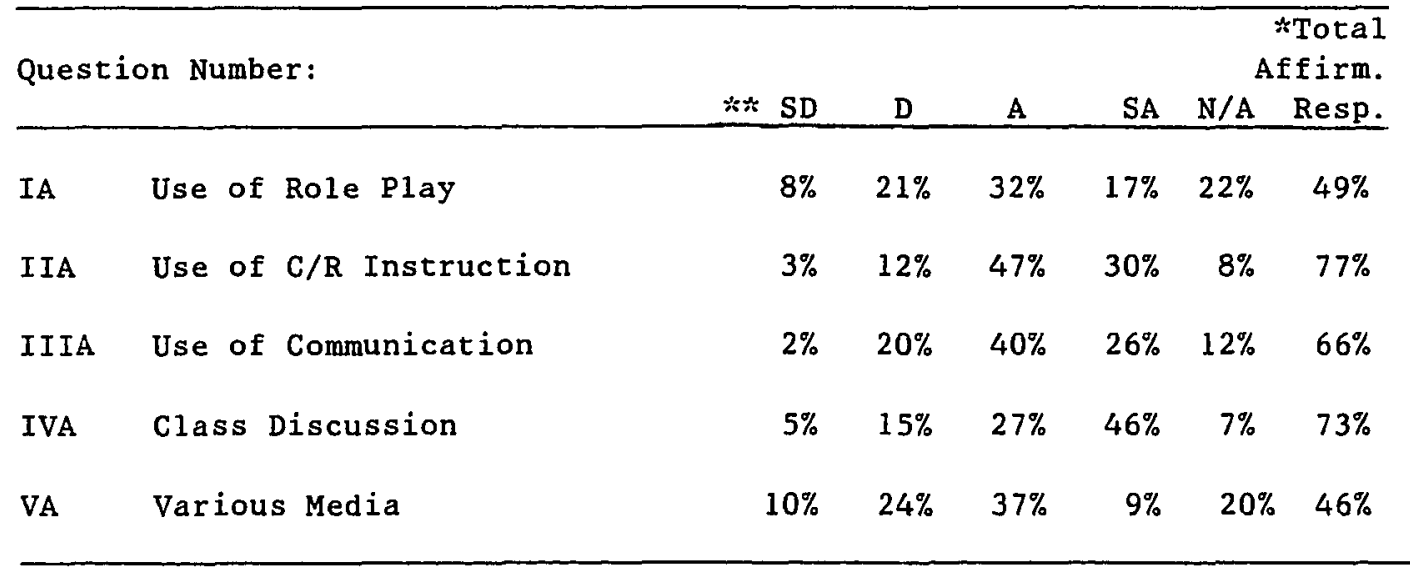

* $\frac{\circ}{\partial}=$ total percent of responses in an affirmative manner.

** SD = strong disagreement with statement;

$\mathrm{D}=$ mild disagreement with statement;

$A=$ mild agreement with statement;

$S A=$ strong agreement with statement;

$\mathrm{N} / \mathrm{A}=$ not applicable. 
Teachers responded to the 47 inquiries on a scale of one to five. In analyzing these responses, "SD" and "D" were scored as a negative response and "A" and "SA" were scored as positive responses. A response of "N/A" was scored as indicating that it was not applicable to the respondent.

Each major item is next divided into subcategories with summary of the frequency analyses of responses after each subquestion. The relationship between these responses will be given at the end of section one.

Use of Role Plays (Question I)

Table IV (p. 48) describes question I, which examines the use of role play. "In my classroom I use role play to teach conflict resolution." Forty-eight percent of the survey respondents indicated that they did, in fact, use role play as a technique to teach conflict resolution. Those who indicated that they used role play as a technique to teach conflict resolution responded to subquestions which describe the manner in which they either conducted that role play or their perception of the effect of that role play technique. (See Table IV.)

IA1. "When I tailor the conflict resolution role play, I allow the students' input into designing the hypothetical situation." Seventy-five percent of those respondents who indicated that they used role play as a technique to teach 
conflict resolution indicated that they allowed students' input into designing the hypothetical situation.

1A2. "When I conduct a conflict resolution role play in my classroom I assign observers (as opposed to allowing participants to act as observers)." Fifty-six percent of those respondents who indicated that they used role play as a technique to teach conflict resolution indicated they assigned observers, as opposed to allowing participants to choose to act as observers.

IA3. "When I conduct a conflict resolution role play I direct student actions as little as possible." Sixty-five percent of those respondents who indicated that they used role play as a technique to teach conflict resolution skills indicated that they directed students as little as possible.

IA4. "When I direct a conflict resolution role play, I am careful to direct students to stay with the specific task assigned." Eighty-four percent of those respondents who indicated that they used role play as a technique to teach conflict resolution skills indicated that they were careful to direct students to stay with the specific task assigned.

IA5. "When I conduct a conflict resolution role play I assign students to specific roles." Eight-six percent of those respondents who indicated that they used role play to teach conflict resolution skills indicated that they assigned students to specific roles. 
IB. "I use conflict resolution role plays at least once a month." Sixty-three percent of those respondents who indicated that they used role play to teach conflict resolution skills indicated that they used conflict resolution role plays at least once a month.

IC. "Role plays are an effective way to teach conflict resolution in my classroom." Ninety-two percent of the respondents who indicated that they used role plays to teach conflict resolution skills indicated that they believed that role plays are an effective way to teach conflict resolution skills in their classrooms.

TABLE IV

POSITIVE RESPONSE PERCENTAGE TO THE CLARIFYING SUBQUESTIONS: USE OF ROLE PLAY

\begin{tabular}{lll}
\hline Question: & Percent \\
\hline IA Use of Role Plays & 48 \\
IA1 Student Input & 75 \\
IA2 Assign Observers & 56 \\
IA3 Little Direction & 66 \\
IA4 Direct Students to Stay w/Task & 84 \\
IA5 Assign Students to Roles & 86 \\
IB Monthly Use & 56 \\
IC Effectiveness & 92 \\
\hline
\end{tabular}

Summary of Responses to Question I. Among respondents to this survey, role play was the fourth technique in terms 
of popularity as a technique for teaching conflict resolution. In analyzing the data collected, it was evident that almost half of the survey respondents used role play as a technique to teach conflict resolution. Those respondents who did use role play as a technique tended to allow their students' input into designing the lessons. The great majority of this question's respondents structured a lesson in such a way as to assign students to specific roles, even assigning non-participants the specific role of "observer." Respondents who indicated that they used role play were careful to direct participant action within the role play as little as possible while assuring that participants remained on task. Well over half of this question's respondents indicated that they involved students in such role play activities at least once a month. Almost all indicated that they believed that such role plays were an effective technique to teach conflict resolution.

Use of Direct Instruction of $\mathrm{C} / \mathrm{R}$ (Question II)

Table V (p. 52) describes Question II, which examines the use of direct instruction in the teaching of conflict resolution. "I instruct my students in conflict resolution techniques." Seventy-seven percent of the survey respondents indicated that they did, in fact, instruct their students in conflict resolution techniques. Those who indicated that they instructed their students in conflict resolution techniques responded to subquestions which 
describe the manner in which they either taught those techniques or their perception of the frequency or effectiveness of that technique. (See Table V.)

IIA1. "When I instruct my students in conflict resolution techniques I instruct students to attempt to identify common interests with adversaries." Seventy-five percent of those respondents who indicated that they instructed their students in conflict resolution techniques indicated that they instructed students to attempt to identify common interests with adversaries.

IIA2. "When I teach conflict resolution I teach students to generate options in solving conflict situations." Ninety-seven percent of those respondents who indicated that they instructed their students in conflict resolution skills indicated that they taught students to generate options in solving conflict situations.

IIA3. "When I teach conflict resolution skills I explain the positive aspects of conflict." Sixty-three percent of those respondents who indicated that they instructed their students in conflict resolution skills indicated that they explained to their students the positive aspects of conflict.

IIA4. "When I teach conflict resolution skills I encourage students to look for legitimate methods of resistance in conflict situations." Seventy-nine percent of the respondents who indicated that they instructed their 
students in conflict resolution skills indicated that they encouraged students to look for legitimate methods of resistance in conflict situations.

IIA5. "When I teach conflict resolution I direct students to determine behaviors which originate the conflict." Ninety-seven percent of the respondents who indicated that they taught conflict resolution skills indicated that they directed students to determine behaviors which originated the conflict.

IIB. "I instruct students in conflict resolution skills at least once a month." Seventy-nine percent of the respondents who indicated that they taught conflict resolution skills indicated that they did so at least once a month.

IIC. "Instructing students in conflict resolution techniques modifies student behavior in dealing with conflict." Ninety-one percent of the respondents who indicated that they taught conflict resolution skills indicated that they believed that instructing students in conflict resolution techniques modifies student behavior in dealing with conflict. (See Table V.) 
TABLE V

POSITIVE RESPONSE PERCENTAGE TO THE CLARIFYING SUBQUESTIONS: USE OF C/R INSTRUCTION

\begin{tabular}{ll}
\hline Question: & Percent \\
\hline IIA Conflict Resolution Instruction & 77 \\
IIA1 Identify Common Interests & 75 \\
IIA2 Generate Options & 96 \\
IIA3 Positive Aspect of Conflict & 63 \\
IIA4 Legitimate Methods of Resistance & 79 \\
IIA5 Determine Behaviors & 97 \\
IIB Monthly Use & 79 \\
IIC Effectiveness & 91 \\
\hline
\end{tabular}

Summary of Question II. Instructing students in conflict resolution techniques was the most popular method of teaching conflict resolution. Analysis of the data indicated that more than three-quarters of the survey respondents use this technique to teach conflict resolution skills. The majority of those who do instruct students in conflict resolution techniques teach students to identify common goals with their adversaries, as well as methods for generating options to conflict. Most of this question's respondents who taught conflict resolution skills taught their students about the positive aspects of conflict and encouraged legitimate methods of resistance. Almost all of this question's respondents indicated that they taught students to seek origins of conflict. More than three- 
quarters of those respondents who indicated that they taught specific conflict resolution skills stated that they did so at least once a month. Almost all of this question's respondents indicated that it was their belief that doing so modified student behavior in dealing with conflict.

\section{Use of Communication (Question III)}

Table VI (p. 55) describes Question III, which examines the use of communication in the teaching of conflict resolution. "I teach specific communication skills for the purpose of teaching conflict resolution." Sixty-seven percent of the survey respondents indicated that they did, in fact, teach their students specific communication skills for the purpose of teaching conflict resolution. Those who did indicate that they taught their students communication skills for the purpose of teaching conflict resolution responded to subquestions which described the manner in which they either taught those techniques or their perception of the frequency or effect of that technique. (See Table VI.)

IIIA1. "In teaching conflict resolution communication skills I teach students to identify positive and inflammatory language and behaviors." Eighty-six percent of those respondents who indicated that they taught specific communication skills for the purpose of teaching conflict resolution indicated that they taught students to identify positive and inflammatory language and behaviors. 
IIIA2. "In teaching conflict resolution communication skills I include instruction in the langauge of emotions (anger, etc.) and behaviors (fighting, bossing, etc.)." Ninety percent of those respondents who indicated that they taught specific communications skills for the purpose of teaching conflict resolution indicated that they included instruction in the language of emotions, (anger, etc.) and behaviors (fighting, bossing, etc.).

IIIA3. "In teaching conflict resolution I include instruction in refusal skills." Ninety percent of those respondents who indicated that they taught specific communications skills for the purpose of teaching conflict resolution indicated that they included instruction in refusal skills.

IIIA4. "In teaching conflict resolution skills I include instruction in active listening." Eighty-three percent of those respondents who indicated that they taught specific communications skills for the purpose of teaching conflict resolution indicated that they included instruction in active listening.

IIIA5. "In teaching conflict resolution skills I teach students how to use 'I' messages." Sixty-eight percent of those respondents who indicated that they taught specific communications skills for the purpose of teaching conflict resolution indicated that they taught students the use of "I" messages. 
IIIB. "I teach specific communication skills for the purpose of conflict resolution at least once a month." Seventy-two percent of those respondents who indicated that they taught communications skills for the purpose of teaching conflict resolution indicated that they taught those communication skills at least once a month.

IIIC. "Instructing students in communication skills for the purpose of conflict resolution modifies student behavior in dealing with conflict." Eighty-six percent of those respondents who indicated that they taught communications skilis for the purpose of teaching conflict resolution indicated that they believe that such instruction modifies student behavior in dealing with conflict.

TABLE VI

POSITIVE RESPONSE PERCENTAGE TO THE CLARIFYING SUBQUESTIONS: USE OF COMMUNICATION

\begin{tabular}{ll}
\hline Question: & Percent \\
\hline IIIA Communication & 66 \\
IIIA1 Positive/Inflammatory Lang./Beh. & 86 \\
IIIA2 Language of Emotions & 90 \\
IIIA3 Refusal Skills & 89 \\
IIIA4 Active Iistening & 83 \\
IIIB Monthly Use & 72 \\
IIIC Effectiveness & 87 \\
\hline
\end{tabular}


Summary of Question III. Third in popularity for a technique for teaching conflict resolution was communication instruction. Analysis of the data indicated that more than half of the survey respondents taught specific communication skills in order to teach conflict resolution. More than three-quarters of this question's respondents indicated that they taught students to identify both positive and inflammatory language and behaviors. The great majority of this question's respondents indicated that they instructed students in the actual language of emotions. Almost all of this question's respondents indicated that they included instruction in refusal skills. Respondents tended to include instruction in active listening and the use of "I" messages. Almost three-quarters of those respondents who used communication instruction as a technique to teach conflict resolution stated that they did so at least once per month. Eighty-six percent of the survey respondents indicated that they believed that such instruction significantly modified students' behavior when dealing with conflict.

\section{Use of Class Discussion (Question IV)}

Table VII (p. 59) describes Question IV, which examines the use of class discussion. "I use class discussion to teach conflict resolution skills." Seventy-three percent of the respondents indicated that they used classroom discussion to teach conflict resolution skills. Those who 
did indicated that they used class discussion to teach conflict resolution responded to subquestions which describe the manner in which they either used class discussion or their perception of the frequency or the effect of that technique. (See Table VII.)

IVA1. "In teaching conflict resolution through class discussion I design a situation in which students are challenged by opposing points of view." Seventy-six percent of the respondents who indicated that they used classroom discussion to teach conflict resolution skills indicated that they designed situations in which students are challenged by opposing points of view.

IVA2. "In teaching conflict resolution through class discussion I design a situation in which specific students actively represent a position." Sixty-four percent of the respondents who indicated that they used classroom discussion to teach conflict resolution indicated that they designed situations in which specific students actively represent a position.

IVA3. "In teaching conflict resolution through class discussion I use heterogenous grouping." Eighty-four percent of the respondents who indicated that they used classroom discussion to teach conflict resolution skills indicated that they used heterogenous groups.

IVA4. "In teaching conflict resolution through class discussion I instruct students in the difference between 
criticism of people and criticism of ideas." Seventy-nine percent of the respondents who indicated that they used classroom discussion to teach conflict resolution skills indicated that they taught students to differentiate between criticism of people and criticism of ideas.

IVA5. "During class discussion of any type I find that controversy results in higher understanding and retention of the subject." Seventy percent of the respondents who indicated that they used classroom discussion to teach conflict resolution skills indicated that they believed controversy occurring during class discussion (of any subject) resulted in higher understanding and retention of the subject.

IVB. "I use class discussion for the purpose of teaching conflict resolution at least once a month." Seventy-nine percent of the respondents who indicated that they used classroom discussion to teach conflict resolution skills indicated that they used this technique at least once a month.

IVC. "Class discussion is an effective way to teach conflict resolution skills." Eighty-seven percent of the respondents who indicated that they used classroom discussion to teach conflict resolution skills indicated that they felt that this technique was effective in teaching conflict resolution. 
TABLE VII

POSITIVE RESPONSE PERCENTAGE TO THE CLARIFYING SUBQUESTIONS: USE OF CLASS DISCUSSION

\begin{tabular}{ll}
\hline Question: & Percent \\
\hline IVA Class Discussion & 73 \\
IVA1 Challenging Points of View & 76 \\
IVA2 Representation of Position & 64 \\
IVA3 Heterogenous Grouping & 84 \\
IVA4 Criticism of People/Ideas & 79 \\
IVB Monthly Use & 78 \\
IVC Effectiveness & 87 \\
\hline
\end{tabular}

Summary of Question IV. Classroom discussion proved to be the second most popular method of teaching conflict resolution. Analysis of the data indicated that almost three-quarters of this question's respondents state that they use classroom discussion to teach conflict resolution skills. More than three-quarters of those respondents indicated that they designed situations in which students are challenged by opposing points of view. Respondents indicated that they tended to design situations in which specific students actively represent a position. More than three-quarters of this question's respondents indicated that they used heterogenous grouping during class discussion and almost three-quarters indicated that they instructed students in the difference between criticism of ideas and criticism of people. The majority of these respondents 
indicated that they believed that controversy during class discussion results in a higher understanding and retention of the subject. More than three-quarters of this question's respondents indicated that they used classroom discussion to teach conflict resolution skills at least once a month and believed that such a technique is an effective way to teach conflict resolution skills.

Use of Various Media (Question V)

Table VIII (p. 62) describes Question V, which examines the use of various media. "I use various media in teaching conflict resolution skills in my classroom." Forty-six percent of the respondents indicated that they used various media to teach conflict resolution skills. Those who did indicate that they used various media to teach conflict resolution responded to subquestions which describe the manner in which they either used various media or their perception of the frequency or effect of those techniques. (See Table VIII.)

VA1. "In designing a lesson to teach conflict resolution skills I present the lesson to the children through the use of puppets." Thirty-five percent of those respondents who indicated that they used various media to teach conflict resolution indicated that they presented conflict resolution lesson to the children through the use of puppets. 
VA2. "In teaching conflict resolution skills I design art lessons in which varying emotions or ways to solve conflict are depicted." Thirty-three percent of those respondents who indicated that they used various media to teach conflict resolution indicated that they designed art lessons in which varying emotions are depicted.

VA3. "In teaching conflict resolution I use stories to explain conflicts." Ninety-three percent of those respondents who indicated that they used various media to teach conflict resolution indicated that they used stories to explain conflicts.

VA4. "In teaching conflict resolution skills I have students act out/draw/read stories about the decisions of famous peacemakers." Fifty-seven percent of those respondents who indicated that they used various media to teach conflict resolution indicated that they have students act out/draw/read about the decisions of famous peacemakers.

VA5. "In teaching conflict resolution I design art/ drama/literature lessons in which varying cultures are depicted." Thirty-nine percent of those respondents who indicated that they used various media to teach conflict resolution indicated that they designed art/drama/literature lessons in which varying cultures are depicted.

VB. "I teach conflict resolution skills through drama/art/literature at least once a month." Forty-eight percent of those respondents who indicated that they taught 
conflict resolution through the use of drama/art/ literature stated that they did so at least once a month.

VC. "Drama/Art/Literature are effectual means to teach conflict resolution." Eighty-four percent of those respondents who indicated that they taught conflict resolution through the use of drama/art/literature indicated that they felt that such means were effective.

TABLE VIII

POSITIVE RESPONSE PERCENTAGE TO THE CLARIFYING SUBQUESTIONS: USE OF VARIOUS MEDIA

\begin{tabular}{clc}
\hline Question: & & Percent \\
\hline VA & Various Media & 46 \\
VA1 & Puppets & 35 \\
VA2 Art & 33 \\
VA3 & Stories & 93 \\
VA4 & Famous Peacemakers & 57 \\
VA5 & Varying Cultures & 39 \\
VB & Monthly Use & 48 \\
VC & Effectiveness & 84 \\
\hline
\end{tabular}

Summary of Question $V$. The least popular method of teaching conflict resolution tended to be those techniques listed as "other media." Although the least popular, almost half of the respondents indicated that they used other media to teach conflict resolution skills. Only considerable less than half of the survey respondents indicated that they 
taught conflict resolution through the use of puppets. Even fewer indicated that they did so through the use of art lessons in which varying emotions are depicted. A few more tended to teach conflict resolution by designing lessons in which varying cultures are depicted. Of the art/drama/ literature techniques, the most popular tended to be those in which the decisions of famous peacemakers are depicted. Just less than half of the respondents who use various media to teach conflict resolution indicate that they do so at least once a month. Well over three-quarters of these question's respondents believe that drama/art/literature are effective means to teach conflict resolution.

\section{Relationships Among Selected Variables}

The Spearman Correlation Coefficient was calculated to determine the relationship between the five major techniques for teaching conflict resolution and demographics (see Table IX). None of the statistical hypotheses that the population correlation is zero was rejected at the .05 level of significance. 
TABLE IX

CORRELATIONS BETWEEN DEMOGRAPHIC CRITERIA AND USE OF FIVE TECHNIQUES FOR THE TEACHING OF $\mathrm{C} / \mathrm{R}$

\begin{tabular}{lcc}
\hline Question & Years & *Grade Level \\
\hline IA Use of Role Play & -.035 & .186 \\
IIA Use of C/R Instruction & -.006 & .221 \\
IIIA Use of Communication & -.010 & .178 \\
IVA Use of Class Discussion & -.166 & .181 \\
VA Use of Various Media & -.023 & .233 \\
\hline
\end{tabular}

* None of the Spearman Coefficients of Correlations were significant at the .05 level.

After survey identification data (name and school) the first demographic query was "Total Number of Years in Teaching." There was a negligible correlation between years of teaching and responses to any of the questions. Correlations ranged from +.006 ("Number of Years in Teaching" and "Instruction in Conflict Resolution Techniques") to +.166 ("Number of Years in Teaching" and "Class Discussion").

The next demographic query was "Grade Taught." There was, again, a low or negligible correlation between respondent's grade level and responses to any of the questions. In questions regarding all techniques, except "Conflict Resolution Instruction" and "Various Media," there was a negligible correlation ranging from +.178 ("Communication Skills") to +.186 ("Role Play"). There was 
a very low correlation between grade level and two questions: "Conflict Resolution Instruction" (+.221) and "Various Media" $(+.233)$.

The relationship among the five major techniques for the teaching of conflict resolution was investigated and the response categories of each technique were partitioned into "used" ( $S A$ and $A$ ) and "did not use" (SD and D) these techniques. The Chi square was next calculated to determine the likelihood that some factor other than chance accounted for the apparent relationships between responses among the five techniques for teaching conflict resolution. The phi test was then conducted to determine the relationships between the various response items. (See Table X.) 
TABLE X

COMPARISONS BETWEEN THE USE OF VARIOUS TECHNIQUES FOR THE TEACHING OF $C / R$

\begin{tabular}{lrrl}
\hline Questions & *Chi Square & Phi & Relationship \\
\hline IA \& IIA & 9.110 & .319 & Low \\
IA \& IIIA & 13.900 & .404 & Moderate \\
IA \& IVA & 13.522 & .394 & Low \\
IA \& VA & 6.240 & .264 & Low \\
IIA \& IIIA & 24.558 & .498 & Moderate \\
IIA \& IVA & 30.750 & .557 & Moderate \\
IIIA \& VA & 4.500 & .220 & Low \\
IIIA \& IVA & 33.744 & .584 & Moderate \\
IIIA \& VA & 10.915 & .350 & Low \\
IVA \& VA & 17.984 & .444 & Moderate
\end{tabular}

* All were significant at the .05 level.

The phi coefficient between responses to questions regarding techniques which respondents indicated they used to teach conflict resolution were of higher significance than those correlated to the demographic data. There was low to moderate correlation between responses to questions regarding those techniques. Many correlations tended to indicate low, but not insignificant relationships between the responses to various questions regarding the teaching of conflict resolution. Low relationships included those between role play and conflict resolution instruction (phi $=$ $+.319)$, role play and class discussion (phi $=+.394$ ), role 
play and various media (phi $=+.264)$, class discussion and various media (phi $=+.220$ ) and communication techniques and various media $($ phi $=+.350)$.

Stronger correlations appeared in other areas. Moderate correlations existed in role play and communication $($ phi $=+.404)$, conflict resolution instruction and communication (phi $=+.498$ ), conflict resolution instruction and class discussion (phi $=+.557)$, communication and class discussion (phi $=+.584)$, and class discussion and various media $(\mathrm{phi}=+.444)$.

\section{COMPARISONS INVOLVING STAFF DEVELOPMENT}

The fourth research question in this study states: "Is there a significant difference between the responses of those respondents who have had specialized staff development training in techniques for teaching conflict resolution and the responses of those teachers from district who did not offer that staff development training?" Comparisons between responses of teachers from districts which supplied that training and responses of teachers which did not do so indicate some differences in the use of various techniques for the teaching of conflict resolution.

Staff development used by West Linn Schools is here defined as the district's involvement in the E.L.N.A. Consortium (Educators Living in a Nuclear Age), in which schools throughout the United States share information about 
the teaching of conflict resolution skills to students of all ages. The Newberg and McMinnville districts are not involved in the E.L.N.A. Consortium.

Table XI presents the percentage of positive ( $S A$ and $A$ ) responses and the use of those techniques in teaching conflict resolution by the teachers in these three participating districts. Table XII summarizes the differences between the responses of teachers from districts which supplied staff development in the teaching of conflict resolution and the responses from teachers from districts which did not do so. Chi Square tests of independence and Phi coefficients are presented in Table XIII (p. 71).

TABLE XI

SUMMARY OF RESPONSES INDICATING USE OF VARIOUS TECHNIQUES FOR THE TEACHING OF $\mathrm{C} / \mathrm{R}$

(Percentage of Positive Responses)

\begin{tabular}{llllllll}
\hline QUESTION & I & II & III & IV & V & VIB & VIC \\
* Newberg & $42 \%$ & $77 \%$ & $54 \%$ & $66 \%$ & $45 \%$ & $85 \%$ & $84 \%$ \\
* McMinnville & $43 \%$ & $82 \%$ & $78 \%$ & $75 \%$ & $48 \%$ & $87 \%$ & $86 \%$ \\
**West Linn & $67 \%$ & $75 \%$ & $78 \%$ & $87 \%$ & $50 \%$ & $100 \%$ & $86 \%$ \\
\hline
\end{tabular}

* Use Positive Action

** Use E.L.N.A. 
TABLE XII

DIFFERENCES BETWEEN RESPONSES OF TEACHERS WHO HAD STAFF DEVELOPMENT FOR THE TEACHING OF C/R AND RESPONSES OF TEACHERS WHO DID NOT

(Using Frequency Analysis)

\begin{tabular}{llrrr}
\hline Question & $\begin{array}{c}\text { West } \\
\text { Linn }\end{array}$ & $\begin{array}{c}* * \text { Newberg } \\
\text { McMinnville }\end{array}$ & Diff. \\
\hline IA Use of Role Plays to & & & \\
& Teach C.R. & $67 \%$ & $43 \%$ & $24 \%$ \\
IIA & C.R. Instruction & $75 \%$ & $80 \%$ & $5 \%$ \\
IIIA & Communication for C.R. & $78 \%$ & $66 \%$ & $12 \%$ \\
IV & Class Discussion & $87 \%$ & $80 \%$ & $7 \%$ \\
V & Various Media & $50 \%$ & $46 \%$ & $4 \%$ \\
VIB Use of Coop. Learning & $100 \%$ & $86 \%$ & $14 \%$ \\
IVC & Effect of Coop Learning & $86 \%$ & $85 \%$ & $1 \%$ \\
\hline
\end{tabular}

* Use E.L.N.A.

** Use Positive Action

Responses from districts which provided training in conflict resolution and responses from districts which had not done so appeared to differ inconsistently.

There was a 24 percent difference between the responses of teachers from districts who had supplied staff development and the responses of teachers from districts who had not done so, with the people from the districts with training responding more favorably to their use of role play.

Responses regarding the use of conflict resolution indicated that those teachers from districts which did not have training in conflict resolution tended to use this 
technique more often than the teachers from the district which had the conflict resolution training.

In responding to the question about "teaching specific communication skills for the purpose of teaching conflict resolution," there was a 12 percent difference between the responses of teachers from districts who had supplied staff development and the responses of teachers from districts who had not done so, with the people from the districts with training responding more favorably to their use of this technique.

In responding to the question about use of class discussion "for the purpose of teaching conflict resolution skills," there was a seven percent difference between the responses of teachers from districts who had supplied staff development and the responses of teachers from districts who had not done so, with the people from the districts with training responding more favorably to their use of this technique.

In responding to the question of using various media "for the purpose of teaching conflict resolution skills," there was a four percent difference between the responses of teachers from districts who had supplied staff development and the responses of teachers from districts who had not done so, with the people from the districts with training responding more favorably to their use of this technique. 
The statistical hypothesis that staff development and the use of various media to teach conflict resolution (item VA) was not rejected (Chi Square $=0.100$ ), therefore the phi of .180 was not significant.

TABLE XIII

DIFFERENCES BETWEEN RESPONSES OF TEACHERS WHO HAD STAFF DEVELOPMENT FOR THE TEACHING OF $C / R$ AND RESPONSES OF TEACHERS WHO DID NOT

(Using Chi Square and Phi Test)

\begin{tabular}{llccl}
\hline Question & Chi Square & Phi & Relationship \\
I Use of Role Play & .06857 & .720 & Negligible \\
II Use of C/R Instruction & 2.200 & .349 & Low \\
III Use of Communication & .690 & .207 & Low \\
IV Use of Class Discussion & .366 & .151 & Negligible \\
V Use of Various Media & .180 & .109 & Negligible \\
\hline
\end{tabular}

None were significant at the .05 level.

A Chi Square was administered to determine if a significant Chi Square factor would indicate that the variable would not exhibit the quality of independence and that they might somehow be systematically related. Examination of the Chi square table indicated that in none of the pairs is there an Chi square finding significant at the .05 level and that the responses may not be systematically related. These relationships do not necessarily transcend pure chance or sampling error. 
The phi test was then administered to determine if there was correlation between the responses of the teachers from districts with staff development training and the responses of teachers without that staff development training. There was little consistency in these correlations. As seen earlier in Table XIII, there is a wide range of correlations to these responses. The two groups of teachers appeared to have little agreement on Question \#1 (Role Play) where phi $=.072$. There was a low correlation (phi $=.207$ ) between the responses in Question $\# 2$ (use of $C / R$ instruction) where phi $=.349$ and Question \#3 (Communication Skills) where phi $=.207$. Question \#4 (Class Discussion) yielded an insignificant correlation (phi = .151), as did Question \#5 (phi = .109).

Although there appear to be some differences in the responses from districts which provide staff development training in conflict resolution instruction and the responses from teachers in districts which do not do so, the differences are inconsistent and it would be improper to suggest a rejection of the hypothesis.

$$
\begin{aligned}
& \text { TEACHER PERCEPTIONS - EFFECTIVENESS OF } \\
& \text { COOPERATIVE LEARNING AS A METHOD FOR }
\end{aligned}
$$

TEACHING CONFLICT RESOLUTION

Question VI was designed to determine whether or not the teachers who used Cooperative Learning felt that this 
teaching technique had, as a by-product, improved student conflict resolution skills. Question VI stated, "Cooperative Learning is not primarily used as a method to teach conflict resolution. Those who use it, however, may or may not see indirect results with students who work with one another. If you regularly use cooperative learning techniques, please respond to the following statements:" Eighty-nine percent of the respondents indicated that they used cooperative learning. Those who did indicate that they used cooperative learning responded to questions which describe their perceptions of the results of that technique.

TABLE XIV

POSITIVE RESPONSE PERCENTAGE TO THE CLARIFYING SUBQUESTIONS: USE OF COOPERATIVE LEARNING

\begin{tabular}{clc}
\hline Question: & & Percent \\
\hline VIA1 & Improved Communications & 80 \\
VIA2 & More Aggressive & 36 \\
VIA3 & Listening Skills & 93 \\
VIA4 & More Passive & 31 \\
VIA5 & Articulation of Feelings & 87 \\
VIB & Monthly Use & 89 \\
VIC & Effectiveness & 85 \\
\hline
\end{tabular}

\section{Use of Cooperative Learning (Question VI)}

"Students who regularly work with one another communicate better than those who do not." Eighty percent 
of those respondents who indicated that they used cooperative learning indicated that it was their perception that students who regularly work with one another communicate better than those students who do not.

VI2. "Students who work regularly with one another are more aggressive than those who do not." Thirty-six percent of those respondents who indicated that they used cooperative learning indicated that it was their perception that students who regularly work with one another are more aggressive than those who do not. Sixty-two percent of those respondents did not perceive that such students were more aggressive. Many comments indicated that they found such students to be more assertive and more confident in their ability to work with others.

VI3. "Students who work regularly with one another are better equipped to listen to their peers than those who do not." Ninety-three percent of those respondents who indicated that they used cooperative learning indicated that it was their perception that students who regularly work with one another are better equipped to listen to their peers than those who do not.

VI4. "Students who regularly work with one another are more passive than those who do not." Thirty-one percent of those respondents who indicated that they used cooperative learning indicated that it was their perception that students who regularly work with one another are more 
passive than those do not. Sixty-seven percent of those respondents indicated that this was not their perception.

VI5. "Students who regularly work with one another tend to be better equipped to articulate feelings than those who do not." Eighty-seven percent of those respondents who indicated that they used cooperative learning indicated that it was their perception that students who regularly work with one another were better equipped to articulate their feelings than those who do not.

VIB. "Students in my class work cooperatively at least once a month." Eighty-nine percent of the survey respondents indicated that they used cooperative learning at least once a month.

VIC. "Students who are involved in cooperative learning groups have better conflict resolution skills than those who do not." Eighty-five percent of the survey respondents indicated that it was their perception that students who are involved in cooperative learning groups have better conflict resolution skills than those who do not.

Summary of question VI. Due to the fact that the survey sections involving techniques for the teaching of cooperative learning differed so greatly in wording, it would not have been valid to compare them in the same manner. It was, however, possible to compare questions regarding the frequency of use and perceived effectiveness 
of techniques for the teaching of conflict resolution with the frequency and effectiveness regarding conflict resolution as a by-product in the teaching of cooperative learning. The researcher then decided to compare those responses to determine a relationship.

The Chi square was conducted to determine the likelihood of some factor other than chance accounting for relationships between the responses to major questions regarding the teaching of conflict resolution and the responses to questions regarding cooperative learning. The Chi Square evaluates the probability that the apparent relationship results from chance. To determine the actual relationship between the responses regarding the use and perceived effectiveness of various techniques for the teaching of conflict resolution and the responses to questions about the use and perceived effectiveness of cooperative learning and the coefficient phi was again may be regarded as the correlation between the attributes $A$ and B when the categories are associated with "scores" of 0 and 1. For this reason the phi test was conducted to determine the relationship between various response items. 
TABLE XV

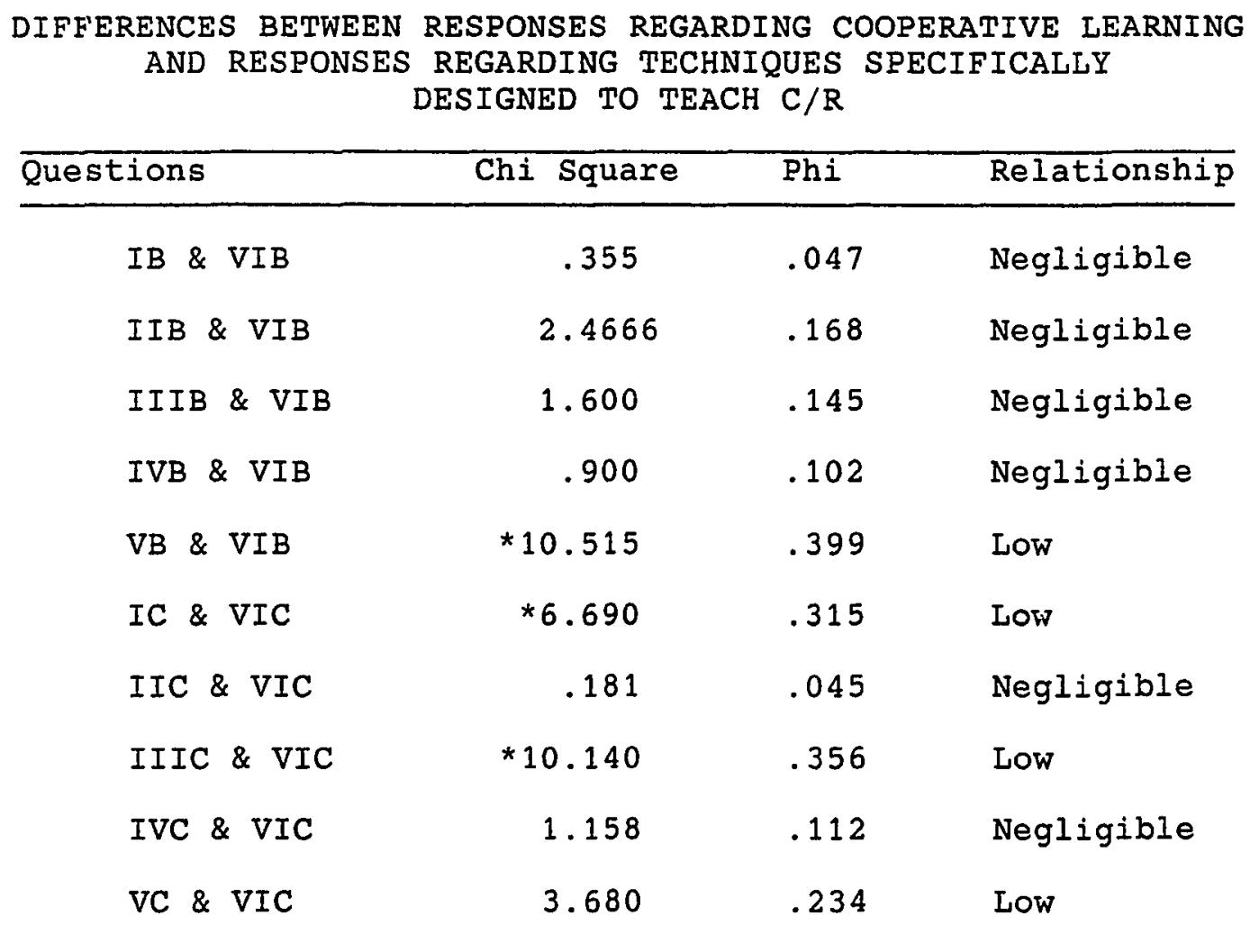

* Significant at the .05 level.

A Chi Square was administered to determine if a significant Chi Square factor would indicate that the variable would not exhibit the quality of independence and that they might somehow be systematically related. Examination of the Chi Square table indicate that in only three of the pairs is there a Chi square finding significance at the .05 level, and that the remainder of the responses may not be systematically related. These relationships do not necessarily transcend pure chance or sampling error. 
The non-significant pairs had phi values ranging from .045 (IIC and VIC) to .234 (VC and VIC). In the case of three pairs, however, it appeared that some factor other than chance may account for the apparent relationship. The relationship between questions VB and VIB (The monthly use of other media and monthly use of cooperative learning) had an Chi Square score of 10.5 which is significant at the .05 level. The corresponding pair was VC and VIC (perceived effectiveness of various media and perceived effectiveness of cooperative learning had an Chi square score of 3.68 which is significant at the .05 level.

The phi test was then administered to determine if there was correlation between the responses regarding teachers' perceptions of use and effectiveness of various techniques for the teaching of cooperative learning and responses regarding use and perceived effectiveness of cooperative learning. There was little consistency in these correlations. As seen in Table XV, there is a wide range of correlations to these responses. The two groups of teachers appeared to have little agreement on Question \#I (monthly use of role play and monthly use of cooperative learning) where phi $=.047$. Such was the case in Question II, where there was an insignificant correlation $(+.168)$ between the questions regarding the monthly use of conflict resolution instruction and cooperative learning (phi $=+.349$ ). There was another insignificant correlation (phi $=+.145)$ between 
the responses in Question \#III (the monthly teaching of communication skills and the monthly teaching of cooperative learning). Paired with Questions VIB, Question IV (monthly use of class discussion) yielded another insignificant correlation (phi $=+.102$ ). The pairing of Questions VB and VIB did, in fact, yield a low correlation of +.399 . Regarding the question of effectiveness of cooperative learning as a technique for the teaching of conflict resolution, there still remained inconsistency. Paired with IC (effectiveness of role play) there was a low correlation of resolution instruction where the phi score was +.04 and VIC (effectiveness of class discussion) where the score was +.112 , there appeared to be insignificant correlation. Questions IIIC and VIC (effectiveness of communication skills and other media) where the phi score was +.234 , there appeared, at least, to be a low correlation.

Cooperative Learning appeared to be widely used among those who responded to the survey. The construction of the survey does not, however, yield results which indicate a difference in the frequency of the use of cooperative learning and the use of techniques for the teaching of conflict resolution. Questions about various techniques for teaching conflict resolution spoke to the manner in which those techniques were used, as well as respondent's perception of the frequency effectiveness of their use. The majority of questions about cooperative learning did not 
speak to cooperative learning as a technique for teaching conflict resolution, rather as a learning mode in and of itself. Comparisons between the responses would not, therefore, supply valid results to compare the frequency of the use of those techniques.

Perceived effectiveness, however, may be determined by comparing effectiveness questions throughout the survey. Each perceived effectiveness question was similarly worded and spoke specifically to the effectiveness of the technique to teach conflict resolution. Cooperative learning was at the mid-range of perceived effectiveness as a method of teaching conflict resolution. Those statistics indicate that respondents perceive that the use of cooperative learning may result in student success in dealing with conflict.

SUMMARY OF RESULTS

The research questions answered are as follows: (Primary Questions)

1. What are teachers' perceptions of the manner in which they teach conflict resolution skills to elementary students?

2. What are teachers' perceptions of the frequency of the use of those techniques?

3. What are teachers' perceptions of the effectiveness of those techniques? 
(Secondary Questions)

4. Is there a significant difference between the responses of teachers from districts which provided related staff development and those teachers from districts who did not provide that staff development?

5. What are teachers' perceptions of the effectiveness of cooperative learning as a technique for teaching conflict resolution skills?

To answer these questions, frequency analyses were conducted to analyze the distribution of teacher responses. A Spearman Correlation Coefficient was conducted to determine the affect of demographic criteria. A Chi square was conducted to determine the level of independence and a Phi Test was used to determine the relationship between various questions.

There was a negligible or low correlation between the responses to demographic data and responses to questions regarding cooperative learning. There was a low to substantial correlation between questions regarding cooperative learning to questions regarding techniques specifically designed to teach conflict resolution. After survey identification data (name and school) the first demographic questions was "Total Number of Years in Teaching." Similar to the spearman results in section one of Chapter IV, there was a negligible correlation between years of teaching and responses to any of the questions. 
The next demographic question was "Grade Level." Similarly, there were negligible correlations between grade level and responses to any of the questions. In the questions regarding the use of cooperative learning, there was a negligible correlation ranging from -.045 ("Grade Level" and "Effectiveness of Cooperative Learning") and .118 ("Years of Teaching" and "Effectiveness of Cooperative Learning"). In all cases there was a negligible correlation between demographic data and responses to cooperative learning.

The correlation between responses to questions regarding the frequency of the use and perceived effectiveness of the use of cooperative learning and all other techniques were of only slightly higher significance than those correlated to the demographic data.

To furnish evidence for accepting or rejecting the three hypotheses statements, the following results bear reporting:

Statistical Hypothesis 1 (Parts A through $\mathrm{J}$ )

A) There is a low relationship (phi $=+.319)$ between the responses of teachers who state that they use role play to teach conflict resolution and the teachers who state that they instruct students in conflict resolution techniques. The null hypothesis was rejected.

B) There is a moderate relationship ( phi $=+.404)$ between the responses of teachers who state that they use role play to teach conflict resolution and the teachers who 
state that they teach specific communication techniques for the purpose of teaching conflict resolution. The null hypothesis was rejected.

C) There is a low relationship (phi $=+.394)$ between the responses of teachers who state that they use role play to teach conflict resolution and the responses of teachers who state that they use classroom discussion to teach conflict resolution skills. The null hypothesis was rejected.

D) There is a low relationship (phi $=+.264)$ between the responses of teachers who state that they use role play to teach conflict resolution and the responses of teachers who state that they use other media to teach conflict resolution skills. The null hypothesis was rejected.

E) There is a moderate relationship (phi $=+.498$ ) between the responses of teachers who state that they instruct their students in conflict resolution techniques and the responses of teachers who state that they teach communication skills for the purpose of teaching conflict resolution skills. The null hypothesis was rejected.

F) There is a moderate relationship ( $\mathrm{phi}=+.557$ ) between the responses of teachers who state that they instruct their students in conflict resolution techniques and the responses of teachers who state that they use classroom discussion for the purpose of teaching conflict resolution skills. The null hypothesis was rejected. 
G) There is a low relationship (phi $=+.220)$ between the responses of teachers who state that they instruct their students in conflict resolution techniques and the responses of teachers who state that they use various media for the purpose of teaching conflict resolution skills. The null hypothesis was rejected.

H) There is a moderate relationship ( $\mathrm{phi}=+.584$ ) between the responses of teachers who state that they use classroom discussion to teach conflict resolution and the teachers who state that they use communication skills for the purpose of teaching conflict resolution skills. The null hypothesis was rejected.

I) There is a low relationship (phi $=+.350)$ between the responses of teachers who state that they teach communication skills for the purpose of teaching conflict resolution skills and the teachers who state that they use various media for the purpose of teaching conflict resolution skills. The null hypothesis was rejected.

J) There is a moderate relationship ( $\mathrm{phi}=+.444$ ) between the responses of teachers who state that they instruct their students in conflict resolution skills and the teachers who state that they use various media for the purpose of teaching conflict resolution skills. The null hypothesis was not rejected. 


\section{Statistical Hypothesis 2}

Throughout the survey results, there was an insignificant to low correlation between demographic criteria and responses to the survey. The null hypothesis was not rejected.

Statistical Hypothesis 3

Comparisons between responses from teachers from districts which supplied that training and responses of teachers from districts which did not do so indicate only a slight difference in the use of various techniques for the teaching of conflict resolution. The null hypothesis was not rejected. 
CHAPTER V

CONCLUSIONS

INTRODUCTION

This study examined elementary teachers' perceptions of the techniques they use to teach conflict resolution skills to their students, teachers' perceptions of the frequency of use of those techniques, as well as teachers' perceptions of the effectiveness of those techniques. It is divided into the following sections (a) summary, (b) conclusions and (c) recommendations.

The purpose of this study was to examine teachers' selfperceptions of the manner in which elementary teachers teach conflict resolution skills to their students. In order to examine the impact of the teaching of those skills, an important first step was to look at current practices. This study examined those practices in three school districts, as well as teachers' perceptions of the frequency and effectiveness of the use of those techniques. In doing so, it is hoped that this research created a benchmark for further study of the teaching of conflict resolution in the elementary classroom. By collecting and synthesizing elementary teachers' self-reports of their techniques of 
teaching conflict resolution, it was a planned outcome of this research to create new knowledge in the area of Conflict Resolution Education.

The research questions answered were as follows: (Primary questions)

1. What are teachers' perceptions of the manner in which they teach conflict resolution skills to elementary students?

2. What are teachers' perceptions of the frequency of use of those techniques?

3. What are teachers' perceptions of the effectiveness of those techniques?

(Secondary questions)

4. Is there a significant difference between the responses of teachers from districts which provided related staff development and those from districts which did not provide that staff development?

5. What are teachers' perceptions of the effectiveness of cooperative learning as a technique for teaching conflict resolution skills?

To answer these questions, a survey was conducted in three Oregon school districts to measure respondents' perception of the manner in which they taught conflict resolution to their students. The respondent pool consisted of 152 teachers in the districts of West Linn, Newberg and McMinnville. The Teacher Perception Survey itself was 
designed by the researcher. The survey, using a likert scale, first asked teachers to respond to questions which examined five major methods for teaching conflict resolution. the survey next asked teachers to respond to questions regarding the effectiveness of Cooperative Learning as a technique for teaching conflict resolution.

Null hypotheses were tested at the .05 level of significance. Data were reported in terms of frequency distribution, The spearman Correlation, a Chi Square and a Phi Test.

Results are reported to furnish evidence for accepting or rejecting the three hypothesis statements. The data from this study supported on of the three hypotheses.

\section{Hypotheses 1}

Hypothesis 1 stated that there were no significant relationships among the responses regarding each of the techniques and tested relationships between each major category. The null hypothesis was rejected in each case. Teachers who make a conscious effort to teach conflict resolution skills to their students appear to do so without exclusive use of a specific technique. Teachers, although tending to favor some techniques, tend to use well more than one technique and sometimes all of them. It may be of some value to determine if teachers' teaching technique choices for the teaching of conflict resolution techniques were 
similar to their teaching technique choices for teaching other subject areas.

\section{Hypothesis 2}

Hypothesis 2 stated that there was no significant relationship between demographic criteria and responses to the survey questions. Throughout the survey results there was insignificant to low correlation between demographic criteria and responses to the survey. It appears that neither grade level nor number of years in the field of teaching are of related to the manner in which teachers instruct their students in conflict resolution techniques. The null hypothsis was not rejected.

\section{Hypothesis 3}

Hypothesis 3 states that there was no significant relationship between the responses of teachers from districts which have been exposed to staff development regarding the teaching of conflict resolution and the responses of teachers from districts who have not been exposed to that staff development. Comparisons between responses from teachers from districts which had that staff development and the responses of teachers from districts which did not indicate only a slight difference between the two groups in the use of various techniques for the teaching of conflict resolution. The null hypothesis was not rejected. 
As this research began, it appeared that teachers from West Linn had the benefit of staff development which exposed them to information regarding the teaching of conflict resolution, and that teachers from Newberg and McMinnville did not have that advantage. Through the course of this study, however, it became evident that Newberg and McMinnville teachers were exposed to training which could, in fact, be considered a type of staff development.

West Linn School District is part of the E.L.N.A. Consortium (Educators for Living in a Nuclear Age) in which schools across the nation share information about the teaching of conflict resolution skills to students of all ages. Teachers and administrators who are involved in this organization attend training sessions in which they learn about new techniques and, in turn, share this information with colleagues. The West Linn School District has been involved in the E.I.N.A. project for $\mathrm{xx}$ years.

Although it appeared that Newberg and McMinnville teachers were not exposed to staff development for the teaching of conflict resolution, such was not the case. Both Newberg and McMinnville Districts use the Positive Action program for students at the elementary level. Positive Action is a packaged program which has a kit and various literature for each elementary grade level. The Positive Action Program is multifaceted; it includes the teaching of conflict resolution skills, but many other goals are part of 
the curriculum, including self-concept, behavior management, focus of control and refusal skills. Positive Action lessons cover the five major techniques surveyed in this dissertation for the teaching of Conflict Resolution.

Positive Action materials is part of the health curriculum in the McMinnville and Newberg School Districts. Teacher inservice on the health curriculum would include information on Positive Action. Therefore, although at the beginning of this study it appeared that west Linn teachers had the benefit of a staff development program for the teaching of conflict resolution and teachers from Newberg and McMinnville did not, such was not the case. Teachers from all three districts have the benefit of some type of staff development regarding the teaching of conflict resolution. The responses between teachers in West Linn and the responses of teachers in Newberg/McMinnville are similar enough to indicate that E.L.N.A. and Positive Action, although not necessarily producing a similar educational outcome, may produce a similarity of response from teachers on this particular survey.

\section{SUMMARY OF RESEARCH QUESTIONS}

Questions 1,2 , and 3

Among respondents to this survey, role play was the fourth technique in terms of popularity as a technique for teaching conflict resolution. In analyzing the data 
collected, it is evident that almost half of the survey respondents used role play as a technique to teach conflict resolution. Instructing students in conflict resolution techniques was the most popular method of teaching conflict resolution. Analysis of the data indicates that more than three-quarters of the survey respondents use this technique to teach conflict resolution skills. Third in popularity for a technique for teaching conflict resolution was communication skills instruction. Analysis of the data indicates that more than half of the survey respondents taught specific communication skills in order to teach conflict resolution. Classroom discussion proved to be the second most popular method of teaching conflict resolution. Analysis of the data indicates that almost three-quarters of the survey respondents state that they use classroom discussion to teach conflict resolution skills. The least popular method of teaching conflict resolution tended to be those techniques listed as "other media." Although the least popular, almost half of the survey respondents indicated that they used other media to teach conflict resolution skills.

\section{Question 4}

The fourth research question states, "Is there a significant difference between the responses of those respondents who have had specialized staff development training in techniques for teaching conflict resolution and the responses of those teachers from districts who did not 
offer that staff development training?" Responses appeared to differ inconsistently. West Linn tended to use role play more than Newberg/ McMinnville. They also tended to teach specific communication skills for the purpose of teaching conflict resolution. There was slightly more use of both class discussion and various media for the purpose of teaching conflict resolution skills. There was not a significant relationship of the two groups surveyed.

\section{Question 5}

Cooperative Learning is not primarily used as a method to teach conflict resolution. Those who use it, however, may or may not see indirect results with students who work with one another. Respondents who regularly used cooperative learning techniques were asked to respond to the following statements regarding the of use of that technique on their students' abilities to resolve conflict.

Cooperative Learning appears to be widely used among those who responded to the survey. The construction of the survey does not, however, yield results which indicate a difference in the frequency of the use of cooperative learning and the use of techniques for the teaching of conflict resolution. Questions about various techniques for teaching conflict resolution spoke to the manner in which those techniques were used, as well as respondents' perceptions of the frequency and effectiveness of their use. The majority of questions about cooperative learning did not 
speak to cooperative learning as a technique for teaching conflict resolution, rather as a learning mode in and of itself. Comparisons between the responses would not, therefore, supply valid results to compare the frequency of the use of those techniques.

Perceived effectiveness, however, may be determined by comparing effectiveness questions throughout the survey. Each perceived effectiveness question was similarly worded and spoke, specifically, to the effectiveness of the technique to teach conflict resolution. Cooperative learning was at the mid-range of perceived effectiveness as a method of teaching conflict resolution. Those statistics indicate that respondents perceive that the use of cooperative learning may result in student success in dealing with conflict.

\section{CONCLUSIONS}

Benjamin Disraeli described friendship as a passion, which enters the being and tears the soul (Pickles, 1988). Teachers have long known that students feel friendship and enmity with profound enthusiasm. Disruptions of that friendship can create conflict which, in turn, has a profound effect on atmosphere in a classroom. Since classroom conflict can infringe on learning time and disrupt bone fide classroom activities, it is essential that teachers be skilled in dealing with conflict. It is also important that 
teachers see conflict resolution instruction as a part of their classrooms' internal curriculum.

This research did not prove that most teachers actually instruct students in conflict resolution skills. Just over half of the teachers to whom the survey was given chose to complete and return the survey. There is no evidence to suggest that those teachers who did not return the survey do, in fact, instruct students in techniques for conflict resolution. This indicates that although the need for conflict resolution is well evidenced in the literature, many elementary teachers may leave this important learning completely out of their instructional plan. It is important that this tendency be addressed and that it be expected that conflict resolution instruction be implicit in the curriculum at each grade level.

Conflict resolution skills may be introduced in a variety of ways. Instructors can, for example, make use of the many teachable moments in their teaching day. A playground disturbance which results in role play to illustrate alternate options can make optimum use of instructional time. Group sharing discussions which elicit information about neighborhood "squabbles" can result in powerful class discussions in which students share solutions and where interactive discussion is modeled and practiced. Incidents in which students display emotional outbursts can result in successful one-on-one discussions in which teachers 
assist the student in exploring those emotions and naming the feeling which is at the root of the disturbance. These examples list teacher actions which, if handled well, may take little class time and actually eliminate further disturbances.

When it is handled correctly, conflict may give students a more accurate representation of different perspectives. Teachers can direct students to use various media to express those perspectives in a thoughtful, productive manner. When students participate in activities in which topical conflict is studied by their exploration of various media, and such media is displayed, students learn one another's perspectives and will hopefully respect these differences. Using various media, students create their own analysis or conclusions. Well handled conflict may have tremendous benefits for increasing students' motivation. A classroom debate about the problem of toxic waste may spark interest and involvement much more readily than a teacher lecture or a science test. Used together, these three methods of instruction can create a stimulating lesson in which students use facts to dispute one another. The careful use of conflict in the classroom may result in higher achievement and greater enjoyment of the instructional experience.

Classroom controversy may enhance or damage classroom learning environments, depending on the expertise with which it is handled. A school environment in which students feel 
safe in expressing emotions but are expected to express them appropriately assists in creating a positive feeling tone throughout the school. The improvement of conflict resolution skills can significantly improve school climate. It is each school's responsibility to create a structure in which that appropriate fee expression can be expressed and students can feel safe, accepted and respected.

Elementary teachers who do, in fact, instruct their students in conflict resolution appear to use a variety of techniques to do so. Although some techniques were clear favorites and were perceived as more effective than others, teachers appeared not to have strong differences of opinion regarding the use of those techniques. Teachers tended to use all techniques as opposed to using one at the exclusion of others. It would be valuable to do further research to determine if these same teachers were as ubiquitous in the teaching of other subjects or if their liberal use of a variety of teaching techniques was limited to the teaching of conflict resolution.

There was no evidence to suggest that number of years of teaching" or "grade level" at which instructors taught had any impact on the way they instructed students conflict resolution skills. It might again be valuable to determine whether or not this lack of correlation between grade level/number of years of teaching and teaching technique could also be found in the teaching of other subjects. 
Cooperative learning proved to be a technique widely used among all teachers surveyed. There are many benefits to the use of cooperative learning, but it is evident that one of the by-products to this learning methods is that students who are involved in cooperative learning groups appear to have better conflict resolution skills than students who are not involved in that learning method. One reason for this may be that five basic elements which are required for cooperative learning are closely aligned to the skills necessary for students to successfully resolve conflict. Positive interdependence is achieved when students' goals, tasks, resources, roles and rewards are interdependent. Cooperative learning also requires that students learn faceto-face interaction among themselves. Individual accountability is required for mastering material assigned. Both interpersonal and small group skills must be taught prior to students successfully working in cooperative learning groups (Johnson, Johnson \& Johnson, 1986).

Involving students in cooperative learning groups may be the most successful way to teach conflict resolution skills. Conversely, teaching conflict resolution skills may be a key element to implementation of cooperative learning groups. All five techniques studied in this research (group discussion, role play, use of various media, communication skills and the teaching of conflict resolution skills) can be 
used in the introduction or refinement of cooperative learning groups.

Students who are involved in cooperative groups eventualiy learn that some type of conflict is inevitable. Well rounded human beings must learn to deal with the disquieting and this aspect of group learning provides an important element to student development.

No matter what the classroom learning style happens to be, students must learn the value of human interaction. They must also learn from their own experience that social relations need not be adversarial and that human beings can share power without losing influence. Students who learn this lesson are better prepared to grow as global citizens.

\section{RECOMMENDATIONS}

The information gleaned by this survey indicates that several considerations are important to a successful implementation of a program to teach conflict resolution. One of the first issues that should be addressed is that conflict is a natural state which accompanies change and can act as a constructive force. It is important to recognize that conflict in the classroom can provide a creative tension to inspire problem solving. Conflict should be handled in such a way as to have benefits for increasing student motivation and should result in higher achievement and 
greater understanding of their subject. Conflict, itself, should prove an effective component to specific lessons. Empathy must be a key ingredient in teaching the resolution of conflict. Students who understand their own emotional make-up and can verbalize those feelings may be better equipped to deal with conflict than peers who do not have such skills. Techniques for teaching resolution of conflict should include age-appropriate instruction in the language of emotion.

The five techniques surveyed (role play, conflict resolution instruction, communication, class discussion, ană various media) are popular and effective methods for the teaching of conflict resolution and are perceived by teachers to be effective.

Conflict in life is inevitable and it is essential that a well-rounded human being has learned to deal with the disquieting. Educators have a responsibility to provide, through various techniques, instructions - not only in the resolution of conflict, but the uses and benefits thereof.

FUTURE STUDY

The teaching of conflict resolution skills is in need of further research in current practices and the effectiveness of those practices. Such research should include the study of the amount and quality of conflict resolution training for teachers. Research should also be conducted about current 
practices for the instruction of conflict resolution in urban and rural school districts, as well as practices at middle and elementary levels.

Future studies should also include both experimental and qualitative work which would attempt to determine relationships between various methods of teaching conflict resolution and the apparent effects of that instruction.

Further studies must also include an analysis of the usefulness of conflict resolution in the learning environment. It is evident that educators should not only learn to manage inappropriate conflict but, in many cases, to make use of that conflict. Appropriately applied, this may enhance the teaching of their subject matter, giving students a better understanding of their peers and significantly enriching motivation. 
Ayers, George. 1976. Conflict Management: Human Relations Training Manuals. Racine Schools, Racine, WI.

Badertscher, James A. 1978. A Study of Elementary Principals' Judgment in Determination of Newly Placed Teachers. Unpublished presentation, University of Oregon. Eugene, OR.

Berg, Marlowe. 1974. "Conflict Encounters Strategy for the Elementary Classroom." The Social Studies Review, Vol. 14, pp. 18-19.

Berman, Louise, and Meil, Alice. 1983. Educating For World Cooperation. Kappa Delta Phi Publishers, West Lafayette, IN.

Best, John and Kahn, James. 1986. Research In Education. Prentice Hall, City, NJ.

Bolman, Lee and Deal, Terrence. 1984. Modern Approaches to Understanding and Managing Organizations. Jossey-Bass Publisìers, San Francisco, CA.

Crary, Elizabeth. 1986. Kids Can Cooperate. Parenting Press, Seattle, WA.

Clair, Mary and others. 1980. Social Conflicts, Multicultural Education. Pomona School District, Pomona, CA.

Davis, Albie. July, 1986. "Dispute Resolution at an Early Age." Negotiation Journal.

Davis, Albie and Porter, Kit. July, 1985. "Dispute Resolution, The 4th ' $R$ ': A Manual for Dispute Resolution." Missouri Journal for Dispute Resolution, pp. $125-129$

Davis, Albie and Porter, Kit. Winter, 1985. "Tales of Schoolyard Mediation." Journal of Resolution and Related Education, V. 9. pp. 120-125. 
Dececco, John and Richards, Gary. Month, 1978. "Using Negotiation to Resolve Teacher/Student Conflict." Journal of Resolution and Development in Education, V II, pp. 64-77.

Deutsch, Morton. June, 1982. "Conflict Resolution: Theory and Practice." Lecture at Teacher's College, Columbia University, as listed in ...

Dittrich, Sandi. April 15, 1987. "Conflict Resolution: A Place in the Classroom." Friends Journal, pp. 12-14.

Dunn, Larry. 1988. The Role Play Book. Mennonote Conciliation Service, Akron, PA.

Edleson, Jeffrey. Month, 1981. "Teaching Children to Resolve Conflict: A Group Approach." Social Work, V. 26, pp. $488-498$.

Elliott, B.M. 1954. "A Study Concerning the Orientation of New Teachers." Unpublished dissertation, Washington University, st. Louis, Miss.

Fischer, Robert and Ury, Joseph. 1981. Getting to Yes. Penguin Books, New York, NY.

Flad, Elizabeth. April, 1989. Interview at Portland state University. Portland, OR.

Fry, Todd. Jan., 1968. "Communication Education and Peace Education." Education, V. 35, pp. 75-80.

Gathercoal, Forrest. 1987. Judicious Discipline. Prakken Publishers, Ann Arbor, MI.

Johnson, David and Johnson, Roger. 1983. "The Social and Achievement Crisis: Are Cooperative Learning Experiences the Solution?" Applied Social Psychology, Annual 4, pp. 119-164.

Johnson, David and Johnson, Roger. 1985. Academic Conflict Among Students: Controversy and Learning Psychology Applications to Educators. Cambridge University Press, Cambridge, MA.

Johnson, David and Johnson, Roger. 1986. "Making Conflicts Constructive in the Classroom." Educational Leadership, v. 10 .

Johnson, David, Johnson, Roger and Holubec-Johnson, Edythe. 1986. Circles of Learning. Interaction Book Company, Edina, MN. 
Kreidler, William. Jan., 1984. "How Well do You Resolve Conflict?" Intructor, pp. 30-33.

Iincoln Nebraska Public Schools. Month, 1982. "Target: Communication Skills." Curriculum Guide, p. 256.

Lodato, Francis. May, 1982. "Developing Conflict Resolution skills." Momentum, V. 2, pp. 25-27.

Meredith, Nikki. August, 1987. "Kids, Communication \& Compromise." Parenting, pp. 63-66.

Mock, Ron. 1988. The Role Play Book. Mennonote Conciliation Service, Akron, PA, p. 1 .

Munnely, Robert J. Feb., 1971. "Is it Time to Break the Silence on Violence?" School Journal, V. 5, pp. 237243 .

Nelson, Janice and Aboud, Frances. Aug., 1985. "The Resolution of Social Conflict Between Friends." Child Development, V. 56, pp. 1009-1017.

Olivero, James L. Jan., 1979. "Rights, Respect \& Responsibility: Those 3R's are Important, Too." Educational Leadership, V. 8, pp. 8-10.

Pickles, Shiela (Ed.). 1988. Treasury of Verse and Prose. Harmony Books, New York, NY, p. 83.

Pirtle, Sarah. 1987. An Outbreak of Peace. New Society Publishers, Philadelphia, PA.

Schmidt, Fran and Friedman, Alice. 1985. Creative Conflict Solving for Kids Grades 4-9. Grace Abrams Peace Education Foundation, Miami, FL.

Schmuck, Patricia and Schmuck, Richard. 1988. Group Process in the Classroom (5th ed.). William C. Brown Pub., City, st.

Schmuck, Richard. 1986 Handbook for Organization in Schools. (3rd ed.). Mayfield Publishers, Mountainview, CA.

Shure, Myrna and Spivak, George. 1982. Mental Health Program for 4-Year Olds. Jossey-Bass Publishers, San Francisco, CA. 
APPENDIX A

TEACHER PERCEPTION SURVEY 


\section{TEACHER PERCEPTION SURVEY}

\section{Cenflice Rerolution in the Classroom}

\section{Instructlons:}

Teaching the social skills of conflict managemunt to elementary students is a crucial and sometimes primary task of elementary school teachers. Myriad techniques for the teaching of those conflict resolution skills exist and those ptople with the most expertise and txperience are, perhaps, the elementary teachers themselves. The purpose of this restarch is to examine the perceptions of elementary teachers regarding the use of those techniquts, the degree of thutir use and their erfectivenuss.

The following statemeats have been chosen to illustrate reachers' perceptions of their role in the teaching of conflict management to elementary students in grades kindergarten through five.

Individual responses to the questionnaire will be not disclosed but group results will be made available to you.

If you are new to the grade level whire you are currently teaching, please answer only for the grade level at which you currently teach.

After you have completed the survey, please place it in the large green envelope in the main orfice labled "Conflict Resolution Survey".

\section{Marking your answers:}

A mark in column "1" represents strone disayreement with the statement.

A mark in colum "2" indicates mild disayromeme with the sta

A mark in column "3" shows mild agreement with the statement. A mark in the bux indicales that the question is NOr APPLICABLE.

Your input is invaluable to this research. I offer my sincere thantis for your time and your expertise.

\section{Sincerely yours,}

Marcia Gregor Garrick

Name (optional)

Date

School District: West Linn Newberg McMinnville Other: (District) Total \# years in teaching

Grade or Area of Spucialty Number of years at this grade level or area of specially 


\section{TEACHER-PERCEPTION SURVEY}

The following statements and substalements are divided into five major calegories. Only respond to the substatements if the main statement is true for you in your class. Again, thankst

ROLE PLAYS: la my classroom I use role plays to teach conflict resolution.
$\begin{aligned} & 1 \\ & \text { (Strong }\end{aligned}$
$\begin{aligned} & \text { Disugreement) } \\ & \text { (Stiong }\end{aligned}$

\section{COMMENT AREA:}

Ayrecment) N/A

If you respanded to statement " $A$ " with a " 3 " or " 4 ". pleuse respond to the following substatements:

1. When 1 tailor the conflict resolution rale play 1 allow the students

inpul into designing the hypothetical siluztion.

2. When I conduct a conflict resolution role play in my classroom I assign obsurvers ( as opposed to allowing participants to act as observers). 1 . 2 as 3

3. When 1 conduct a conflict resolution role play I direct student actions as little as possible.

3
4

4. When I conduce a conflict sesolution role play I am careful 10 direct siludents 10 stay with the specific task assignted.

$$
23
$$

5. Whan I conduct a conflict resolution role play $l$ assign students to specific roles.

$$
1
$$

$$
2
$$$$
3
$$

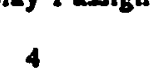

B. I use conflict resolution role plays at least once a month.

C. Role plays are an effective way to teach conflict resolution in my classroom.

1

3

4

Additional Comments:

Resources/Programs used in teaching through role play: 
II. A. CONFLICT RESOLUTION INSTRUCTION: I lostruct my students in confilet

resolution techniques.

\begin{tabular}{|c|c|}
\hline $\begin{array}{l}1 \\
\text { (Strung } \\
\text { isagreenient) }\end{array}$ & $\begin{array}{c}4 \\
\text { (Strong } \\
\text { Agrement) }\end{array}$ \\
\hline
\end{tabular}

COMMENT AREA:

Disagretenent) Aurkement) N/A

If you responded 10 stalement "A" with a "3" or " 4 ", please respond to the following substatements:

1. When I teach conflict resolution skills $I$ instruct students to attempt to identify common interests with adversaries.
3

1

\begin{abstract}
4
\end{abstract}
2. When I leach conflict resolution I leach sludents to gentratc options

in solving conflicl siluations.

3

3. When I teach conflict resolution I explain the positive aspects of conflict.
1

$$
2
$$
3

4 positive aspects of

4. When I teach conflict resolution I encourage students to look for legitimate methods of resistance in conflict situations.

123

4

When I teach conflict resolution I direct students to determine behaviors which originated the conflict.

34

B. J instruct students in conflict resolution techniques at least once a month. 2

3

C. Instructing students in conflict resolution techniques modifies student

behavior in dealing with conflict.

Additional Comments:

Resources/Programs used in teaching conflict resolution instruction: 
III. A. COMMUNICATION: I teach specific commualcation sklils for the purpose of teachiog conflict resolution.

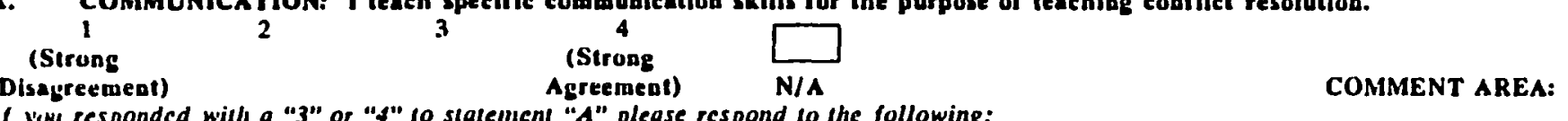

If yuu responded with a " 3 " or "f" 10 statement "A" please respond to the following:

AREA:

1. In teaching conflict resolution communication skills I twach sludents to identify positive and inflammalory language and behaviors.

posilive and inflammalory languagl and hehaviors.

2. In teaching conflict resolution communication skills 1 include instruction in the language of emolions (anger, ctc.) and hehaviors (fighting, hossing, elc.). 2

3. In teaching conflict resolution $I$ include instruction in refusal skills.
1
2
3

\begin{abstract}
4
\end{abstract}
$\square$

4. In teaching conflict rusolution skills $I$ include instruction in active listening.
2
4
44

5. In teaching conflict resolution skills I teach students how to use "l" messages.

$1 \quad 2 \quad 3 \quad 4$

4

B. I teach specific communication skills for the purpose of conflict resolution at least once a month.

1 least once a month.

3

c. Instructing students in communication skills for the purpose of conflict resolution modifies student behavior in dealing with conflict.

Additional comments:

Rcsourcus/programs used in teaching through communication:

IV. A. Class discussion: 1 use class discession to teach conflict resolution skills. $\begin{array}{lllll}1 & 2 & 3 & 4\end{array}$ (Strang

4 (Stron Abrement) N/A

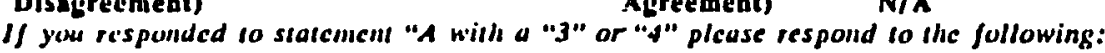

1. In teaching conflict resolution through class discussion 1 design a situation in which studenis are challenged by opposing points of view. 
2. In teaching conflict resolution through class discussion I design a situation in which

specific students actively represent a position.

3. In teaching conflict resolution through class discussion I use heterogenous grouping. 1 2 3

4. In teaching conflict resolution through class discussion 1 instruct students in the difference between criticism of ptople and criticism of idtas.
1
4

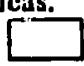

5. During class discussion (of any subject) I find that controversy results in a higher

$$
\text { understanding and retention of the subject. }
$$

B. I use class discussion for the purpose of twaching conflict resolution at least once a month.

C. Class discussion is an effective way to teach conflict resolution skills.

Additional comments:

Rusources/programs used in teaching through class discussion:

V. A. DRAMA AND ART: I use various media in teachlag confliet resulution skills in my claysroom.

COMMENT AREA: 
5. In leaching conflict resolution skills I design art/drama/litcrature lessons in which

varying cultures are depicted.

3

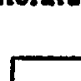

B. I teach coaflict resolution skills through drama/art/literature at least once a month.

c. Drama/art/litcrature are effectual means to teach conflict resolution.

1 2 3

Additional comments:

Resources/programs used in teaching through drama, art and literature:

VI. COOPERATIVE LEARNING: Cooperative luarning is not primarily used as a method of conflict resolution. Those who use it, however, may or may not sut indirect results with students who work with one another. If you regularly use cooperative learning techniques please respond to the following statements

1. Students who regularly work with one another communicate better than those who do not.

$\begin{array}{ccccc}1 & 2 & 3 & 4 & \\ \text { (Struags } & 2 & \text { (Strong } & \\ \text { Alsagreement) } & & & \text { Ayreement) } & \text { N/A }\end{array}$

2. Students who regularly work with one another are more aggressive than those who do not.
4

3. Students who regularly work with one another are better equipped to listen to their

pecrs than those who do not. 3

Siudents who regularly workwith one another are more passive than those who do not.

2

4

5. Students who regularly work with one another tend to be better equipped to

articulate feclings than those who do not.

B. Students in my class work cooperatively at least once a month.
1
2
3
4

C. Studeats who are involved in cooperative learning groups have

better conflict resolution skills than thuse who do not.

1

4

Additional commeats:

Resources/programs used in teaching through couperative learning:

COMMENT AREA:

COMMENT AREA: 
APPENDIX B

LETTER TO ADMINISTRATORS 
Dear Administrator:

Thank you for your interest in my research and your willingness to encourage your faculty to participate in this survey .

The surveys will arrive on __ (date) and my representative will place them into your teachers' mailboxes. Your secretary will be given a large green envelope to collect all completed surveys.

Again, thank you so much for your interest and support.

Sincerely,

Marcia Gregor Garrick 